NATALY VASCONCELLOS SANTOS DE ANDRADE

\title{
Relação entre a dinamometria isocinética e a incidência de lesões musculoesqueléticas em atletas de futebol de salão na fase pré temporada
}

Dissertação apresentada à Faculdade de Medicina da Universidade de São Paulo para obtenção do título de Mestre em Ciências

Área de Concentração: Fisiopatologia Experimental Orientadora: Profa. Dra. Júlia Maria D’ Andrea Greve

São Paulo 2008 
Dados Internacionais de Catalogação na Publicação (CIP)

Preparada pela Biblioteca da

Faculdade de Medicina da Universidade de São Paulo

Creprodução autorizada pelo autor

Andrade, Nataly Vasconcelos Santos de

Relação entre a dinamometria isocinética e a incidência de lesões

musculoesqueléticas em atletas de futebol de salão na fase pré temporada / Nataly Vasconcelos Santos de Andrade. -- São Paulo, 2008.

Dissertação(mestrado)--Faculdade de Medicina da Universidade de São Paulo para obtenção do título de Mestre em Ciências.

Área de concentração: Fisiopatologia Experimental.

Orientadora: Júlia Maria D’Andrea Greve.

Descritores: 1.Futebol 2.Avaliação 3.Torque 4.Músculo esquelético/lesões

USP/FM/SBD-294/08 


\section{DEDICATÓRIA}

Dedico este trabalho aos meus amados e queridos pais: Juarez de Andrade e Nancy Vasconcellos Santos de Andrade. 


\section{AGRADECIMENTOS}

Agradeço primeiramente a Deus, pela oportunidade concedida de realizar um sonho de estudar nesta Universidade que tanto honro e admiro.

Agradeço de todo meu coração à minha querida e tão carinhosa orientadora, Dra. Júlia Maria D’Andrea Greve, por toda sua brilhante orientação em toda minha formação após a graduação, mas principalmente por confiar em mim e acreditar em meu sonho desde o início. Agradeço também pela sua dedicação, paciência e elegância em me ajudar em todos os momentos que eu necessitei, não se opondo nunca e agradeço pelas horas que desfrutamos juntas, que me tornaram com toda certeza um ser humano e uma profissional melhor.

Agradeço imensamente à Profa. Dra. Sílvia Maria Amado João, ao Prof. Dr. Fábio Passos e ao Prof. Dr. André Pedrinelli pelas excelentes e fundamentais orientações que me foram oferecidas no Exame de Qualificação.

Agradeço aos meus pais, Juarez de Andrade e Nancy Vasconcellos Santos de Andrade, pelo esforço constante em me ajudar, impulsionar, amparar, amar e principalmente confiar em mim e em minha capacidade.

Agradeço à minha irmã, tão amada e inteligente, que com suas palavras concisas, porém fortes, sempre me ajudou e me deu força para seguir confiante.

Agradeço aos meus amigos queridos: Camila Pires, Miguel Posi Filho, Nelson Sanches, Flávia Mautone, Luciana Beraldi, Patrícia Penha, Patricia Alfredo, Lélia Miranda, Cássio Siqueira, Ronald Gonçalves, Laura Vieira, José Maria de Morais, Janete Canales por todo entendimento e carinho.

Agradeço aos atletas e todos os profissionais envolvidos neste trabalho, sem os quais o mesmo não seria possível.

Agradeço aos meus familiares por todo incentivo, amor e momentos de alegria nesta ESSENCIAL fase da minha vida.

Ao querido leitor, pelo interesse. 
Esta dissertação está de acordo com as seguintes normas, em vigor no momento desta publicação:

Referências: Adaptado de International Commitee of Medical Journals Editors (Vancouver)

Universidade de São Paulo. Faculdade de Medicina. Serviço de Biblioteca e Documentação. Guia de apresentação de dissertações, teses e monografias da FMUSP. Elaboração por Anneliese Carneiro da Cunha, Maria Júlia de A.L. Freddi, Maria F. Crestana, Marinalva de Souza Aragão, Suely Campos Cardoso, Valéria Vilhena. $2^{\text {a }}$ ed. São Paulo: Serviço de Biblioteca e Documentação; 2005.

Abreviaturas dos títulos dos periódicos de acordo com List of Journals Indexed in Index Medicus. 


\section{SUMÁRIO}

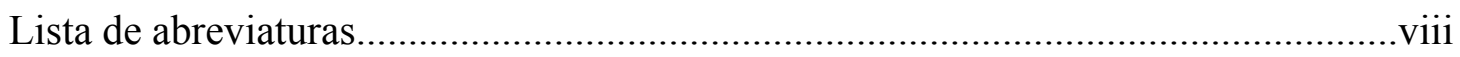

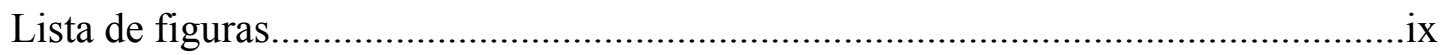

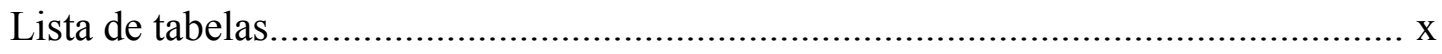

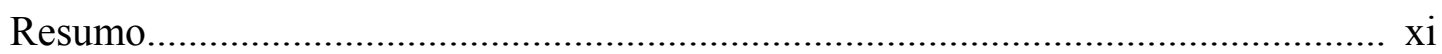

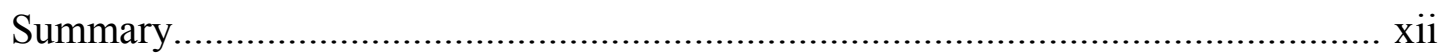

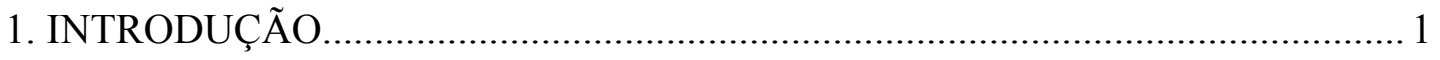

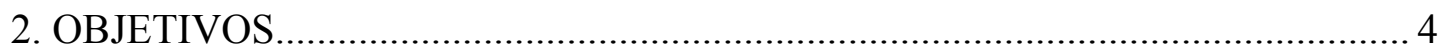

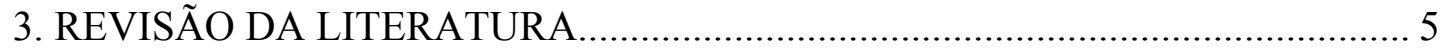

3.1 Lesão musculoesquelética na prática esportiva............................................... 5

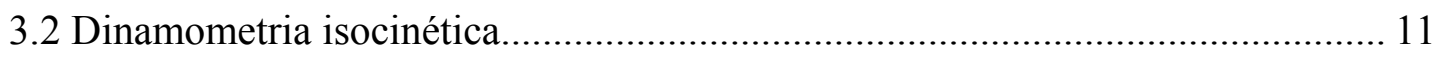

3.3. Futebol de salão e treinamento físico......................................19

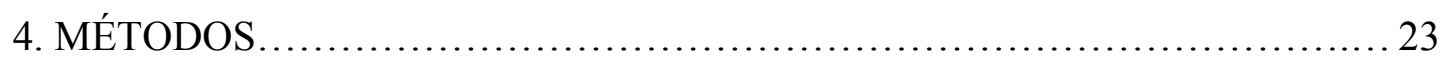

4.1. Análise da Casuística........................................................ 23

4.2. Avaliação Clínica........................................................... 26

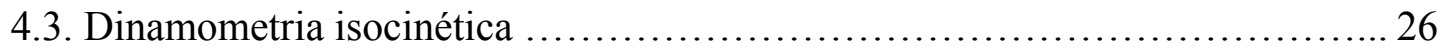

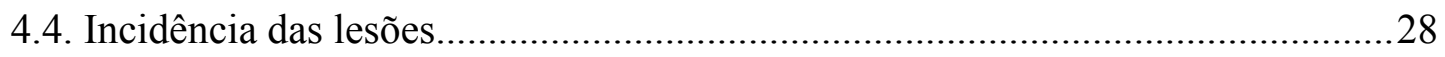

4.5. Estatística...................................................... 29

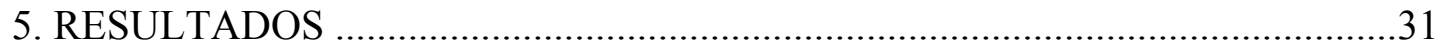

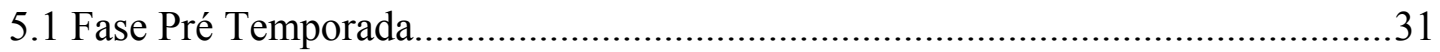

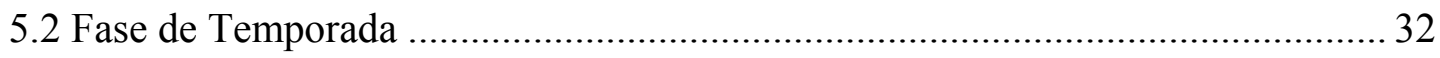

5.3 Correlações entre a avaliação isocinética e as lesões músculoesqueléticas...........35 


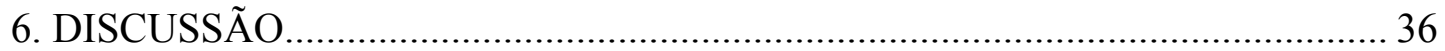

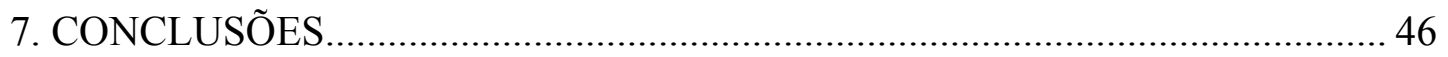

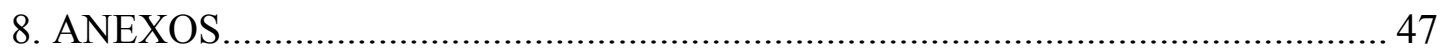

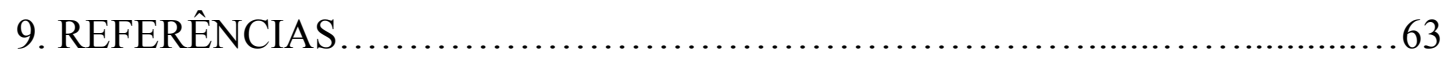




\section{LISTA DE ABREVIATURAS}

\begin{tabular}{ll}
$\%$ & Por cento \\
s & Graus \\
$\leq$ & Segundos \\
$\geq$ & Menor ou igual \\
/s & Maior ou igual \\
ADM & Por segundo \\
Cm & Amplitude de movimento \\
DP & Centímetros \\
IQT & Desvio padrão \\
Kg & Isquiotibiais \\
m & Quilograma \\
ME & Metro \\
MD & Metações por minuto \\
MND & Membro dominante \\
\hline
\end{tabular}




\section{LISTA DE FIGURAS}

Figura 1- Representação gráfica da porcentagem dos sujeitos segundo posição de jogo..................................................... 26 


\section{LISTA DE TABELAS}

Tabela 1 - Valores médios e desvio padrão dos dados antropométricos dos sujeitos e porcentagem de sujeitos com membro dominante direito

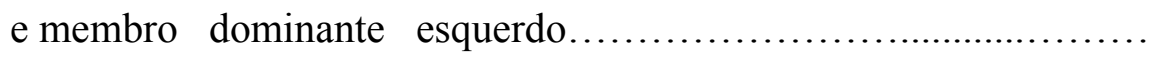

Tabela 2 - Valores médios, medianas, desvio padrão (DP) e p-valor das variáveis quantitativas dos músculos flexores e extensores de joelho do membro dominante e não dominante corrigidos pela massa corporal e expressos em porcentagem nas velocidades de $60 \%$ s e $180^{\circ} /$ s na pré temporada $(n=92)$

Tabela 3 - Distribuição, porcentagem e $p$-valor das lesões músculoesqueléticas sofridas pelos sujeitos durante a temporada, segundo topografia.......

Tabela 4 - Distribuição, porcentagem e $p$-valor das lesões músculoesqueléticas sofridas pelos sujeitos durante a temporada, segundo diagnóstico.....

Tabela 5 - Distribuição, porcentagem e $p$-valor das lesões músculoesqueléticas sofridas pelos sujeitos durante a temporada, segundo local, tipo de lesão e topografia 


\section{RESUMO}

Andrade NVS. Relação entre a dinamometria isocinética e a incidência de lesões musculoesqueléticas em atletas de futebol de salão na fase pré temporada [Dissertação]. São Paulo: Faculdade de Medicina, Universidade de São Paulo; 2008. 67p.

INTRODUÇÃO: O aumento da prática do futebol de salão como lazer ou desempenho trouxe mais lesões do sistema musculoesquelético, que passaram a exigir maior atenção e cuidados dos profissionais de saúde. OBJETIVO: Avaliar os parâmetros da dinamometria isocinética dos músculos flexores e extensores do joelho na fase pré temporada, verificar a incidência de lesões musculoesqueléticas de membros inferiores nos jogadores de futebol de salão e fazer a relação entre as lesões e a função muscular. MÉTODOS: Foram avaliados 92 jogadores de futebol de salão. A avaliação isocinética foi feita por meio do dinamômetro isocinético Cybex, modelo Norm nas velocidades angulares de $60^{\circ}$ /segundos e $180^{\circ} /$ segundos. Durante a temporada de jogos foi realizada a coleta das lesões. Foram analisados o pico de torque, o trabalho total e a relação flexora/extensora corrigidos pela massa corporal e expressos em porcentagem. Os dados foram submetidos a análises descritivas (média, desvio padrão e porcentagem) e foram utilizados os testes de Wilcoxon e Kruskal-Wallis para comparações das variáveis quantitativas e qualitativas $(P<0,05)$. RESULTADOS: Diferenças significantes foram encontradas na pré temporada para o pico de torque flexor, relação flexora/extensora a $60^{\circ} / \mathrm{s}$ e trabalho flexor total para as duas velocidades, sendo que o lado dominante apresentou valores maiores. A lesão predominante foi a entorse de tornozelo em ambos os membros, sem diferença significante. Não foram observadas diferenças estatisticamente significantes entre as lesões e as variáveis da dinamometria isocinética. CONCLUSÃO: Este estudo sugere que os jogadores de futebol de salão têm alterações nas variáveis isocinéticas, nos membros dominantes e nos membros não dominantes, dependendo da velocidade angular, porém não há relação entre tais lesões musculoesqueléticas e as variáveis isocinéticas.

Descritores: 1.Futebol 2.Avaliação 3.Torque 4.Músculo esquelético/lesões 


\section{SUMMARY}

Relation between isokinetic dynamometry and the incidence of musculoskeletal injuries during pre-season period in indoor soccer players. [dissertation]. São Paulo: "Faculdade de Medicina, Universidade de São Paulo"; 2008. 67p.

INTRODUCTION: The increasing number of indoor soccer players, both in amateur and in professional teams, has given rise to more injuries to the musculoskeletal system, calling more attention and demanding greater care of healthcare providers. AIMS: To assess the parameters of isokinetic dynamometry in knee flexors and extensors muscles during pre-season period, detect the incidence of lower limb musculoskeletal injuries in indoor soccer players and establish a relation between injuries and muscular function. METHOD: Ninety-two indoor soccer players were assessed. Isokinetic assessment was conducted by using a Cybex isokinetic dynamometer, Norm model at angular velocities of $60^{\circ} / \mathrm{sec}$. and $180^{\circ} / \mathrm{sec}$. During the regular soccer season all injury events were recorded. Peak torque, total muscular work and flexor/extensor ratio corrected for body mass were analysed and expressed as a percent scale. Descriptive analysis of data (mean, standard deviation and percentage), as well as Wilcoxon and Kruskal-Wallis tests for comparison of quantitative and qualitative variables $(P<.05)$ were performed. RESULTS: In the run-up to the season, significant differences were found for flexor peak torque, flexor/extensor ratio at $60^{\circ} \% \mathrm{~s}$ and total flexor work for the two speeds. The dominant side showed higher values. Ankle strain was the prevailing injury in both limbs, and the difference was not significant between both. No statistically significant differences were observed concerning injuries and isokinetic dynamometry variables. CONCLUSION: The results of the study suggest that indoor soccer players have changes in isokinetic variables, in both dominant and non-dominant limbs, depending on the angular velocity, although no relation between musculoskeletal injuries and such isokinetic variables was found.

Descriptors: 1.Soccer 2.Assessment 3.Torque 4.Muscle skeletal/injuries 


\section{INTRODUÇÃO}

O futebol de salão é um esporte cada vez mais praticado em todo mundo, com um crescente aumento no número de atletas participantes. Devido à facilidade em encontrar espaços para sua prática, diferentemente do futebol de campo, este é um dos esportes mais disseminados no Brasil (Arnason et al., 1996; Metzel e Micheli, 1998; Melo, 1999; CBFS, 2001; USFF, 2001, Ribeiro et al., 2003).

O futebol de salão se caracteriza por uma sucessão de movimentos de alta velocidade, em espaços reduzidos (cinco a dez metros), com contínuas trocas de direção e sentido, intercalados com pausas, que não permitem recuperação completa, sendo assim uma sucessão de atividades anaeróbias e aeróbias (Medina et al., 2002). Os ciclos são altamente imprevisíveis, pela espontaneidade do jogador e padrões de jogo (Barbanti, 1996).

A posição dos jogadores varia de acordo com a função exercida : goleiro, fixo, alas direita ou alas esquerda e pivô.

As lesões musculoesqueléticas (ME) podem estar relacionadas com fatores intrínsecos: idade, lesões prévias, instabilidade articular, preparação física e habilidade ou fatores extrínsecos como: sobrecarga, número de jogos, qualidade das quadras, equipamentos e violações às regras dos jogos (Arnason et al., 1996; Bjordal et al., 1997; Cohen e Abdalla, 2002).

Com o aumento do número de praticantes, as lesões vêm se tornando cada vez mais freqüentes, exigindo maior atenção e cuidado dos profissionais da área da saúde (Lindenfeld et al., 1994, D’Hooge et al., 1994; Putukian et al., 1996, Serrão et al., 2000; Ribeiro et al., 2003). 
Alguns fatores responsáveis pelas lesões no futebol, entre outros esportes, são: contato com o oponente, condições do campo/quadra, treinamento, alterações posturais, desequilíbrios musculares ou déficits (Ekstrand e Gillquist, 1983; Nielsen e Johannes, 1989; Inklaar, 1994; Ribeiro, 2003). O treinamento intensivo e repetitivo de uma modalidade esportiva proporciona a hipertrofia muscular e a diminuição da flexibilidade, causando desequilíbrio entre a musculatura agonista e antagonista. Além disso, o excesso de treinamento pode causar lesões decorrentes do superuso, como microtraumas devido ao atrito entre duas ou mais estruturas, e levar a quadros de estiramentos musculares, condromalácia, contusões, tendinites, bursites, lombalgias, lesões ligamentares e fraturas (Ekstrand e Gillquist, 1983; Lindenfeld et al., 1994; Putukian et al., 1996; Carazatto, 1992; Junge e Dvorak, 2004; Stewien e Camargo, 2005).

As lesões dos jogadores de futebol de salão predominam nos membros inferiores pela maior vulnerabilidade aos movimentos de alta velocidade e paradas bruscas em espaços restritos. A articulação do joelho é uma das mais estudadas em jogadores de futebol, tanto pelo grande número de lesões que esta articulação apresenta como também pela sua importância em relação ao gesto esportivo do futebol (Engström et al., 1990; Perrin, 1993; Lindenfeld et al.; 1994; Putukian et al., 1996; Goslin e Charteris, 1999; Terreri e Greve e Amatuzzi, 2001; Cohen, 2002; Zakas et al., 2006). Os músculos da articulação do joelho são fundamentais para o chute e na manutenção do equílibrio necessário às mudanças de direção com paradas bruscas. O conhecimento dos mecanismos de lesão do joelho no futebol de salão associados à avaliação da capacidade funcional dos atletas são importantes para prevenção e reabilitação das lesões (Ekstrand e Gillquist, 1983; Nielsen e Johannes, 
1989; Engström et al., 1990; Carazzato et al., 1992; Inklar, 1994; Lindenfeld et al., 1994, Putukian et al., 1996; Cohen et al., 1997; Ribeiro et al., 2003, Junge e Dvorak, 2004; Stewien e Camargo, 2005; Gioftsidou et al., 2006; Zakas, 2006).

A relação entre a função muscular e as lesões músculo-esqueléticas dos membros inferiores nos jogadores de futebol de salão pode identificar alguns fatores de risco e contribuir para a prevenção e melhora do desempenho esportivo.

A possível relação existente entre a função muscular e a incidência de lesões musculoesqueléticas dos membros inferiores poderá sugerir programas de prevenção, identificar fatores de risco na prática do futebol de salão e melhorar os programas de treinamento e reabilitação. Além disso, pode-se investigar se os déficits encontramse em velocidades mais altas ou mais baixas e quais capacidades musculares estão mais comprometidas. Dessa forma, será possível fornecer e utilizar estas informações no programa de treinamento dos atletas e indicar estas velocidades para avaliação e reabilitação, caso necessário. 


\section{OBJETIVOS}

Objetivos gerais:

- Avaliar a relação entre a função muscular dos músculos flexores e extensores do joelho medida por meio da dinamometria isocinética na fase pré temporada;

- Verificar a incidência de lesões musculoesqueléticas de membros inferiores nos jogadores de futebol de salão.

Objetivos Específicos:

- $\quad$ Fazer a relação da incidência e tipo de lesões musculoesqueléticas de membros inferiores com a dominância do membro e a função muscular. 


\section{REVISÃO DA LITERATURA}

A revisão de literatura mostra alguns aspectos importantes na análise dos resultados da pesquisa: conceitos de futebol de salão e treinamento físico, conceito de lesão na prática esportiva, incidência de lesões ME dos atletas na prática esportiva e avaliação por meio da dinamometria isocinética.

\subsection{Lesão musculoesquelética na prática esportiva}

Mcmaster e Walter (1978) e Sullivan et al. (1980) definiram lesão músculoesquelética do esporte como qualquer queixa clínica que ocorra durante os jogos ou treinamentos e impeçam o atleta de continuar a praticar as atividades motoras.

Ekstrand e Gillquist (1983) e Nielsen e Johannes (1989), definiram lesão como um incidente que ocorre durante jogos ou treinamentos e levam ao jogador a perder o próximo jogo ou treinamento.

Ekstrand e Gillquist (1983) classificaram as lesões em três categorias de acordo com a gravidade: menor (ausência da prática esportiva por menos que uma semana), moderada (ausência da prática esportiva por mais que uma semana e menos que um mês), grande (ausência da prática esportiva por mais de um mês). Os autores consideraram como relevantes o mecanismo de lesão; e o atendimento pós lesão, incluindo o atendimento médico. Estudaram 180 jogadores de futebol com idade variando de 17 a 38 anos, durante o período de um ano e encontraram 256 lesões ME. 
A incidência de lesão para um jogador durante o ano foi de 0,88 por ano para lesões de menor gravidade, 0,38 por ano para moderada gravidade e 0,16 por ano para grande gravidade. De todas as lesões ocorridas, $88 \%$ foram localizadas nos membros inferiores, sendo $20 \%$ no joelho, $17 \%$ no tornozelo, $27 \%$ na coxa, $12 \%$ na perna, $12 \%$ no pé. As entorses representaram $29 \%$ de todas as lesões, sendo $93 \%$ destas envolvendo o tornozelo (59\%) e o joelho (34\%). Nielsen e Johannes (1989) avaliaram 123 jogadores de futebol, sendo 93 jogadores com mais de 18 anos e 30 jogadores com idade de 16 a 18 anos. Foram encontradas 109 lesões, sendo que as mais freqüentes (84\%) também foram localizadas nos membros inferiores: $36 \%$ das lesões ocorreram no tornozelo, $22 \%$ na coxa, $18 \%$ no joelho e $8 \%$ no pé. As entorses representaram $68 \%$ de todas as lesões ocorridas, as tendinites representaram $16 \%$, as contusões representaram $9 \%$ e as fraturas representaram $7 \%$.

Em 1983, Ekstrand, Gillquist e Lijedahl e em 1989, Ekstrand e Nigg, sugeriram em seus estudos que a adequada estabilização do tornozelo ou a utilização de bandagem elástica e exercícios profiláticos são efetivos na prevenção das lesões no tornozelo e demais lesões no futebol.

Noyes et al. (1988) Schmidt-Olsen et al. (1991) definiram lesão no jogador de futebol de acordo com alguns critérios: 1.primeiros socorros, tratamento médico e reabilitação como determinantes do tempo perdido de prática esportiva ou jogo; 2. necessidade de tratamento (médico, fisioterapêutico ou físico) para continuar jogando e 3. diagnóstico e localização anatômica da lesão.

Brynhildsen et al. (1990) estudaram atletas do sexo feminino, praticantes de futebol, o conceito de lesões prévias e as dividiram em: lesões traumáticas e lesões por sobrecarga. Avaliaram 115 jogadoras de futebol e foi encontrada incidência de 
0,18 lesão/ jogador/ ano. As entorses na extremidade inferior também foram as lesões mais comuns, sendo as entorses de joelho e tornozelo as lesões predominantes.

Ainda em 1990, Engström et al. analisaram três times de futebol durante um ano, com um total de 64 jogadores com idade média de 24 anos. Segundo o diagnóstico, as entorses (34\%) foram mais freqüentes, seguidas pelas tendinites e bursites $(33 \%)$ e pelas contusões $(13 \%)$. A maioria das lesões ocorreram nos membros inferiores (93\%); sendo 33\% no joelho, $22 \%$ no tornozelo, $12 \%$ na virilha, $11 \%$ na perna, oito por cento na coxa e sete por cento no pé. Segundo à gravidade da lesão, $27 \%$ das lesões foram consideradas de pequena gravidade, $39 \%$ como moderada e $34 \%$ como grande.

Carazzato et al. (1992) realizaram atendimento em 1.625 jogadores de futebol de salão e 281 jogadores de futebol e analisaram o número de lesões por modalidade, o tipo de lesão e o segmento corpóreo atingido. No futebol de salão foram encontradas 11.173 lesões nos membros inferiores, destas 347 (23,35\%) ocorreram na coxa, $359(22,09 \%)$ ocorreram no joelho, $280(17,23 \%)$ no tornozelo e 187 (11,5\%) no pé. No futebol, foram encontradas 241 lesões nos membros inferiores, destas $88(31,65 \%)$ ocorreram no joelho, 56 (23,38\%) no tornozelo, $47(16,91 \%)$, na coxa, $25(8,99 \%)$ no pé e $26(5,75 \%)$ na perna. Quanto ao tipo de lesão, no futebol de salão predominaram as entorses $(23,38 \%)$, seguidas pelas roturas musculares $(20 \%)$, contusões $(15,13 \%)$ e lesões meniscais e ligamentares de joelho $(11,93 \%)$. No futebol, o tipo de lesão mais comum encontrada foi a entorse $(23,48 \%)$, seguida pela roturas musculares $(17,79 \%)$, lesões meniscais e ligamentares de joelho $(13,16 \%)$ e contusões $(11,03 \%)$. Foi concluído que o futebol de salão é mais lesivo que o futebol de campo. 
Pedrinelli (1994) após avaliar 354 lesões em jogadores de futebol, concluiu que a contusão é a lesão traumática mais freqüente, o joelho é o segmento corpóreo mais acometido e que as lesões traumáticas e agudas são as mais freqüentes e as lesões por contato com outro atleta são as menos freqüentes. Com relação a faixa etária, a maior ocorrência de lesões foi o período entre 25 e 28 anos. Com relação à dominância dos membros inferiores e posição do atleta, não há predominância de lesões no membro dominante dos atletas e não há diferença significativa entre as posições do atleta e o número de lesões.

Lindenfeld et al. (1994) e Junge e Dvorak (2000a) definiram que um atleta seria considerado lesionado se uma das seguintes condições existissem: a) o jogador abandonasse o jogo por uma lesão, b) a lesão requisitasse que o jogo fosse parado, ou c) o jogador requisitasse atendimento médico e diagnóstico de lesão anatômica. Lindenfeld et al. (1994) analisaram 123 jogos de futebol de salão durante um período de 7 semanas. Os times de futebol de salão foram divididos em grupos segundo a idade, menor que 12 anos, de 12 a 15 anos, de 16 a 18 anos, de 19 a 24 anos e 25 anos ou mais. As lesões foram computadas pelo número de lesões para cada 100 horas jogadas, sendo um total de 1.548 horas jogadas. Foram encontradas 78 lesões nos jogadores de futebol de salão, sendo que 30 destas lesões ocorreram no grupo de jogadores com mais de 25 anos. Com relação ao tipo de lesão, as lesões ligamentares de joelho e tornozelo foram as lesões mais comuns, representando $30 \%$ do total das lesões. As contusões musculares representaram a segunda lesão mais comum, com 23,5\% de todas as lesões. Com relação ao segmento corpóreo acometido, as lesões predominaram no tornozelo $(23 \%)$ e joelho $(23 \%)$, seguido pela cabeça $(12,5 \%)$. Com relação à posição de jogo, os goleiros lesionaram com maior freqüência os 
dedos, a cabeça, mãos e cotovelos; enquanto os jogadores de linha lesionaram com maior freqüência o tornozelo ou joelho.

Putukian et al. (1996), definiram lesão como qualquer perda de tempo de treinamento ou jogo avaliado em um questionário completado pelo técnico. Analisaram 69 times de futebol de salão, representados por 824 jogadores dos Estados Unidos, Inglaterra e Canadá durante três dias de Torneio de Futebol de Salão. Os times que participaram do torneio: homens (open men's), mulheres acima de 30 anos (over - 30 men's), mulheres (open women's) e misto (mixed). As lesões foram computadas pelo número de lesões para cada 100 horas jogadas, com um total de 855 horas jogadas. Foram encontradas 38 lesões, das quais $71,1 \%$ ocorreram na extremidade inferior comparada com $15,8 \%$ de lesões na cabeça ou face e $13,2 \%$ na extremidade superior. Entorse de tornozelo (26,3\%) foi a lesão mais comum, seguida pela lesão ligamentar de tornozelo $(18,4 \%)$ e contusão $(15,8 \%)$. Com relação à gravidade da lesão: $65,8 \%$ das lesões foram de menor gravidade, $15,8 \%$ de gravidade moderada e $18,4 \%$ de grande gravidade.

Cohen et al. (1997) após analisarem 214 jogadores de futebol profissional de 1992 a 1995, com idade de 16 a 40 anos, encontraram 964 lesões. 72,2\% destas lesões ocorreram nos membros inferiores, $16,8 \%$ em cabeça e tronco e $6 \%$ nos membros superiores. Houve predomínio das lesões em coxa $(34,5 \%)$, tornozelo $(17,6 \%)$ e joelho (11,8\%). Quanto ao diagnóstico das lesões, as lesões musculares $(39,2 \%)$ predominaram, seguidas das contusões $(24,1 \%)$, entorses $(17,9 \%)$, tendinites $(13,4 \%)$ e das fraturas e luxações $(5,4 \%)$. Com relação à posição de jogo, foi encontrada maior número de lesões nas posições de meio-campo e menor número de lesões nos goleiros. 
Segundo Junge e Dvorak (2004) em artigo de revisão, as lesões no futebol ocorrem predominatemente no tornozelo, joelho e músculos da perna e coxa. Os tipos mais comuns de lesões são as entorses e as contusões e a maioria das lesões no futebol ocorrem por trauma. Uma importante causa das lesões no futebol é o contato com o oponente e $12 \%$ a $28 \%$ de todas as lesões são atribuídas ao jogo.

Stewien e Camargo (2005) investigaram a ocorrência de entorse de joelho e lesões em jogadores das equipes de futebol da $1^{\circ}$ Divisão do Estado do Amazonas de ambos os sexos. Foram entrevistados e examinados 97 atletas, sendo 50 do sexo masculino com idade média de 26,7 anos e 47 do sexo feminino com idade média de 23,5 anos. Entre os jogadores, as lesões mais freqüentes foram as entorses no joelho (32\%), sendo $28 \%$ unilateral e quatro por cento bilateral. Entre as jogadoras, foram encontrados $23 \%$ de entorses no joelho, sendo $19 \%$ unilateral e quatro por cento bilateral. Com relação à posição de jogo, 29,5\% eram meio campista, 29,5\% defensores e $22 \%$ atacantes.

Ribeiro e Costa (2006) investigaram a incidência de lesões no futebol de salão durante o XV Campeonato Brasileiro de Seleções sub 20. Os médicos, fisioterapeutas ou preparadores físicos das 10 seleções participantes responderam a um formulário para investigar a ocorrência de lesões durante os jogos. Quando um jogador se lesionava, os detalhes de sua lesão eram registrados numa entrevista com o autor principal. $\mathrm{O}$ autor manteve contato regular com fisioterapeutas, técnicos e como os atletas por telefone, para acompanhar a evolução das lesões, após o término do torneio. As contusões $(31,25 \%)$ e as entorses $(28,12 \%)$ foram as lesões mais comuns e quanto à localização anatômica, as lesões predominaram nos músculos da 
coxa $(28,12 \%)$, perna $(25 \%)$, seguidas pelo tornozelos $(18,75 \%)$ e joelhos $(12,5 \%)$. O estudo foi feito para caracterizar a especificidade do futebol de salão.

\subsection{Dinamometria Isocinética}

O conceito e os princípios do movimento isocinético foram introduzidos na década de 60 por Hislop e Perrin e desde então, com a melhora dos equipamentos, a avaliação das capacidades musculares se incorporou na rotina de avaliação dos atletas de alto desempenho (Wrigley e Grant, 1995; Wrigley, 2000).

Ao mensurar as capacidades musculares exercidas sobre o sistema articular, deve-se considerar o torque desenvolvido pelos grupos musculares. Torque é o produto de uma força pelo comprimento do braço de alavanca onde atua esta força e reflete o componente rotacional de força a um sistema de alavancas, sendo mensurado em newtons/ metro. Os torques gerados pelos grupos musculares podem ser determinados através dos dinamômetros isocinéticos, que permitem quantificar outras variáveis do desempenho muscular, sendo elas: o trabalho muscular total que é a tensão produzida por um músculo e representa a energia despendida durante a contração muscular, sendo mensurado em joules; a potência que é a relação entre o trabalho e o tempo necessário para o mesmo, sendo mensurada em watts; a resistência que é a capacidade de manutenção de um trabalho muscular por um período prolongado e a relação agonista/ antagonista que demonstra o equílibrio entre a ação do músculo agonista e antagonista, detectando desequílibrios na ação muscular e podendo predizer possíveis lesões (Hagood et al., 1990; Shinzato e Batistela, 1996; Mcardle et al., 1998; Magalhães et al., 2004; Greve, 2007). 
O conceito equílibrio muscular é um parâmetro importante para a realização adequada da prática esportiva. A dinamometria isocinética tem sido utilizada nas últimas três décadas para se determinar e analisar os padrões de equílibrio funcional, sendo seu uso ainda mais expressivo nas duas últimas décadas (Terreri et al., 2001; D’Alessandro et al., 2005).

A dinamometria isocinética pode avaliar e treinar o músculo de forma objetiva, quantitativa e fidedigna (precisão dos dados através de uma norma pré-estabelecida de medida). O sistema permite calibração para assegurar a precisão dos testes; é reprodutível (controle dos parâmetros da avaliação), permitindo a mensuração dos resultados de forma quantitativa (Cybex, 1996; D’ Alessandro et al., 2005).

A avaliação do desempenho muscular humano tem sido protagonista de muitos estudos, principalmente com o esforço para desenvolver terapias de sucesso para o tratamento de lesões musculoesqueléticas, tanto como para identificar deficiências na função muscular. A função muscular entre os membros dominante e não dominante de jogadores de futebol, tal como de atletas de outros esportes, tem sido ponto de várias pesquisas (Kalapotharakos et al., 2006, Zakas, 2006).

Goslin e Charteris (1979) descreveram a técnica de posicionamento empregada para avaliação isocinética de joelho e propuseram dados normativos para as posições mais usadas na avaliação da articulação. Foram avaliados 30 homens e 30 mulheres, todos sem qualquer história de lesão de membros inferiores, no dinamômetro isocinético Cybex II, avaliados na posição sentada e em decúbito ventral (prono). A amplitude de movimento (ADM) para ambas posições foi de zero graus a $90^{\circ}$ de flexão de joelho. Todos os testes foram realizados a $30^{\circ} / \mathrm{s}$ com três séries de cinco repetições para cada membro. $\mathrm{O}$ membro com maior torque durante o teste na 
posição sentada foi definido como dominante. Não houve diferença no torque máximo dos músculos extensores do lado direito e esquerdo nos homens e nas mulheres. Houve diferença no torque máximo entre os membros dominantes e não dominantes. O membro dominante apresentou valores significantemente mais altos que o membro não dominante. A relação quadríceps/isquiotibiais (IQT) deve ser aproximadamente 2:1 na velocidade testada.

Zakas et al. (1995), avaliaram o pico de torque e a relação agonista/ antagonista dos músculos extensores e flexores do joelho de jogadores de futebol e basquetebol. Foram avaliados 51 jogadores de futebol por meio do dinamômetro isocinético Cybex II, nas velocidades de $60 \%$ e $180 \%$ s. Cada sujeito realizou aquecimento de cinco minutos na bicicleta ergométrica, seguido por alongamento supervisionado dos músculos quadríceps e IQT. Os jogadores foram avaliados na posição sentada com o joelho posicionado em $90^{\circ}$ de flexão. Foram realizados três testes para cada velocidade angular com 30 segundos de descanso entre cada teste e 60 segundos de descanso entre cada velocidade. Com relação ao músculo quadríceps, não houve diferenças significantes entre os jogadores na velocidade de $180^{\circ} / \mathrm{s}$, porém diferenças significantes foram encontradas à velocidade de $60^{\circ}$ s. Com relação aos músculos IQT, foram encontradas diferenças significantes entre os jogadores de futebol na velocidade de $180^{\circ} / \mathrm{s}$, porém diferenças não significantes foram encontradas à velocidade de $60^{\circ} / \mathrm{s}$. Não foram encontradas diferenças significantes na relação agonista/ antagonista entre os jogadores para ambas velocidades. Concluiu-se assim que o peso corporal dos sujeitos tem um efeito decisivo na produção dos valores de pico de torque dos músculos quadríceps e IQT nos jogadores de futebol e basquetebol. 
Bennell et al. (1998), realizaram um estudo prospectivo para avaliar a força concêntrica e excêntrica e a relação entre o torque dos músculos quadríceps e IQT e se esta poderia ser preditora de lesão nos músculos IQT em jogadores australianos de futebol. Analisaram 102 jogadores de futebol, dos quais 89 tinham o membro direito como dominante. Os testes foram realizados no dinamômetro isocinético KinCom, na posição sentada, na amplitude de movimento de cinco graus a $95^{\circ}$ de flexão de joelho. Foram utilizadas as velocidades de $60^{\circ} / \mathrm{s}$ e $180^{\circ} / \mathrm{s}$. Foram realizados cinco a seis movimentos para cada contração, com um intervalo de 60 segundos entre cada. O diagnóstico de estiramento de IQT era feito de acordo com os seguintes critérios: (a) dor nos músculos IQT durante jogo ou treinamento; (b) dor nos músculos IQT com a presença de contração concêntrica ou excêntrica (alongamento); (c) dor à palpação; (d) injúria grave o suficiente para levar ao jogador perda do jogo. 12 dos 102 jogadores tiveram um ou mais sinais diagnósticos clínicos de lesão nos músculos IQT; dois jogadores tiveram estiramento muscular; oito das 14 lesões foram confirmadas por ultra - som; nove no membro direito e cinco no esquerdo. Não houve diferenças significantes entre os membros dominante e não dominante, entre os jogadores lesionados e não lesionados, e entre os grupos com e sem lesão na relação flexora/ extensora. O risco de estiramento de IQT subseqüente não diferiu entre os jogadores, exceto para a contração excêntrica a $180^{\circ}$ s. Como conclusão: avaliação isocinética foi incapaz de discriminar entre jogadores lesionados e não lesionados ou predizer lesão.

Para avaliar os efeitos da idade no pico de torque isocinético dos músculos do joelho de jogadores de futebol, Akova et al. (1999) avaliaram 25 jogadores de futebol, com idade de 18 a 28 anos, agrupados em adultos, maior ou igual a 21 anos 
( $\geq 21$ anos) e jovens, menor ou igual a 21 anos $(\leq 21$ anos). Os resultados também foram avaliados de acordo com a posição de jogo (defesa, meio-campo e atacante). Foi utilizado o Cybex 6000, com os jogadores na posição sentada e ADM de $10^{\circ}$ a $90^{\circ}$ de flexão. Os jogadores realizaram três séries sub-máximas para se familiarizarem com o movimento e após 20 segundos de repouso, realizaram quatro contrações consecutivas máximas dos músculos quadríceps e IQT, nas velocidades de $30 \% \mathrm{~s}, 180 \% \mathrm{~s}, 240 \% \mathrm{~s}, 300 \%$ s. Primeiramente, os sujeitos realizaram os testes concêntricos e após 20 minutos de descanso, os testes excêntricos eram realizados, com 20 segundos de repouso entre cada contração. Para todas as velocidades angulares, não foram encontradas diferenças significantes no torque excêntrico máximo dos músculos quadríceps no membro dominante e não dominante entre os dois grupos etários. Não foram encontradas diferenças significantes para o pico de torque concêntrico, (todas as velocidades angulares) entre os dois grupos etários no membro não dominante. No membro dominante, os pico de torque concêntrico dos músculos quadríceps foram maiores nos adultos do que nos jovens nas velocidades de $180^{\circ} / \mathrm{s}, 240^{\circ} / \mathrm{s}$ e $300^{\circ}$ s. Não foram encontradas diferenças significantes para os picos de torque concêntrico e excêntrico dos músculos IQT entre os dois grupos para o membro não dominante, para todas velocidade angulares. Entretanto, os picos de torque concêntrico e excêntrico dos músculos IQT no membro dominante foram maiores nos adultos do que nos jovens para as velocidades de $180 \% \mathrm{~s}, 240 \% \mathrm{~s}, 300 \% \mathrm{~s}$. O pico de torque concêntrico dos músculos IQT a $240^{\circ} / \mathrm{s}$ foi maior para o membro dominante no grupo de adultos. Não foram encontradas diferenças significantes entre os membros dominante e não dominante no grupo de jovens com relação ao pico de torque concêntrico dos músculos quadríceps. Para todas velocidades angulares, não 
houve diferenças significantes entre os grupos baseados na posição de jogo, assim como para os membros dominantes e não dominantes. Concluiu-se assim, que os achados do presente estudo indicaram que o pico de torque obtido no membro dominante dos jogadores é influenciado pela idade.

Cometti et al. (2001) fizeram a dinamometria isocinética no equipamento Biodex para avaliar o pico de torque concêntrico e excêntrico dos músculos extensores e flexores de joelho, além de avaliar também a potência anaeróbica de um grupo de 95 jogadores de futebol franceses. Os dados foram coletados para verificar se existiam diferenças entre os jogadores da elite, subelite e amadores. Do total de jogadores, 29 eram da primeira divisão, 34 eram da segunda divisão e 32 eram amadores. A avaliação isocinética foi realizada com o sujeito na posição sentada a $90^{\circ}$ de flexão de joelho. Três séries consecutivas eram realizadas para cada velocidade angular. Contrações concêntricas foram realizadas nas velocidades de $60^{\circ} / \mathrm{s}, 120^{\circ} / \mathrm{s}, 180^{\circ} / \mathrm{s}, 240^{\circ} / \mathrm{s}, 300^{\circ} / \mathrm{s}$, e as contrações excêntricas nas velocidades de $60^{\circ} / \mathrm{s}, 120^{\circ} / \mathrm{s}$. Havia um período de três minutos de descanso entre cada série. Os picos de torque dos músculos IQT dos jogadores de elite foram significantemente maiores que nos amadores, exceto a $300 \%$ s. O pico de torque dos músculos IQT dos jogadores de subelite foram significantemente maiores do que nos amadores. Com relação aos músculos extensores, a relação IQT/ quadríceps foi maior para o grupo de elite, comparando-os com os amadores, exceto a $300 \%$ s. O salto vertical, 10 $\mathrm{m}$ de sprint, $30 \mathrm{~m}$ de sprint e velocidade máxima da bola (mensurada por um radar de alta freqüência) durante o jogo também foram mensurados. Velocidade máxima da bola durante o chute e $30 \mathrm{~m}$ de sprint não foram diferentes significantemente entre os jogadores, enquanto que sprint de $10 \mathrm{~m}$ foi significantemente menor no grupo de 
amadores e maior nos grupos da primeira e segunda divisão. Concluiu-se com o estudo: 1. o desempenho no futebol não é determinado somente por fatores físicos; 2. jogadores profissionais diferem dos amadores em termos de força muscular do joelho e sprint de curta distância; 3. força de IQT é extremamente importante em jogadores de futebol para estabilizar o joelho durante as tarefas.

Ergün et al. (2004), realizaram um estudo transversal com o objetivo de avaliar a capacidade muscular isocinética e a frouxidão ligamentar do joelho do membro dominante de jogadores de futebol. Avaliaram um total de 44 jogadores de futebol e 44 sujeitos sedentários saudáveis, como grupo controle. As avaliações da capacidade muscular foram feitas no Cybex II nas velocidades de $60^{\circ} / \mathrm{s}, 180^{\circ} / \mathrm{s}$ e $300^{\circ} / \mathrm{s}$. A avaliação da frouxidão ligamentar foi feita por meio de um artrômetro KT-1000. Neste estudo, o membro utilizado para mobilidade foi considerado o dominante, enquanto o membro de suporte, o não dominante. O pico de torque dos IQT e a relação agonista/antagonista a $180^{\circ}$ s foram significantemente maiores no lado dominante comparando com o lado não dominante, para os jogadores de futebol. O grupo de jogadores apresentaram valores de pico de torque extensor e flexor mais altos que o grupo de sedentários em ambos os lados, assim como a relação flexora/extensora. Os picos de torque a $60^{\circ} / \mathrm{s}$ e $300^{\circ} / \mathrm{s}$ para os lados dominantes não foram diferentes significantemente entre os grupos. Com relação à frouxidão, os jogadores apresentaram menor frouxidão ligamentar, quando comparados com o grupo controle, porém não apresentaram diferenças significantes entre os membros dominantes e não dominantes. Os autores concluíram que não foi possível estabelecer uma relação entre a capacidade muscular isocinética e a frouxidão ligamentar de joelho. 
Newman et al. (2004) realizaram um estudo com a proposta de investigar as relações entre força de membros inferiores e o desempenho na corrida em um grupo de jogadores representados por diferentes tipos de futebol (futebol e rugby). Foram avaliados 14 jogadores de futebol, livres de qualquer lesão. A avaliação isocinética dos músculos flexores e extensores do joelho foi realizada com o dinamômetro Kin Com, com os sujeitos na posição sentada e em três velocidades, a $60^{\circ} / \mathrm{s}, 150 \%$, $240^{\circ}$ s. As contrações foram realizadas numa $\mathrm{ADM}$ de $15^{\circ}$ a $80^{\circ}$. A avaliação do desempenho na corrida foi feito através do teste de sprint. Os valores de pico de torque extensor foram diminuídos significantemente à medida que a velocidade era aumentada, e os valores de pico de torque flexor na velocidade de $240^{\circ} / \mathrm{s}$ foram significantemente diferentes das velocidades de $60^{\circ} / \mathrm{s}$ e $150 \%$ s. A maior correlação observada entre o desempenho na corrida e o pico de torque foi observada entre o torque extensor a $240 \%$ s e na fase de aceleração da corrida.

Gioftsidou et al. (2006) avaliaram isocineticamente o joelho de 35 jogadores de futebol, com o objetivo de detectar possíveis desequílibrios musculares. O teste foi realizado na posição sentada, numa $\mathrm{ADM}$ de zero graus a $100^{\circ}$, com as velocidades angulares de $60^{\circ} / \mathrm{s}$ e $180 \%$ s. Desequílibrios entre os músculos flexores e extensores nos diferentes lados foram encontrados em 15 jogadores de futebol: 22\% para os extensores e $17 \%$ para os flexores à velocidade de $60^{\circ} / \mathrm{seg}, 24 \%$ para os extensores e $19 \%$ para os flexores à velocidade de $180^{\circ} / \mathrm{seg}$. Diferenças na relação agonista/ antagonista também foram encontradas: $51 \%$ à $60 \%$ e $58 \%$ à $180^{\circ} / \mathrm{s}$. Após serem detectados tais desequílibrios, os jogadores foram submetidos a um programa de treinamento isocinético específico por dois meses, três vezes por semana para corrigir os desequílibrios e os déficits e promover ótima resposta neuromuscular. Foi 
concluído que a aplicação da avaliação isocinética é útil para examinar possíveis desequílibrios entre os grupos musculares do joelho e que a aplicação do programa de treinamento pode eliminar diferenças e restaurar pico de torque normal.

Zakas (2006) utilizou a dinamometria isocinética para avaliar e comparar dados sobre o pico de torque extensor e flexor dos músculos do joelho em jogadores de futebol profissional que possuíam dominância em um membro inferior com aqueles que possuíam dominância em ambos os membros. O autor avaliou 42 jogadores de futebol, divididos em três grupos. 15 jogadores com membro direito como dominante, 12 com o membro esquerdo como dominante e 15 jogadores ambidestros. As avaliações foram realizadas no dinamômetro isocinético Cybex Norm, com os sujeitos na posição sentada, nas velocidades angulares de $12 \%, 60^{\circ} / \mathrm{s}, 180^{\circ} / \mathrm{s}, 300^{\circ} / \mathrm{s}$ e com uma $\mathrm{ADM}$ de $0^{\circ}$ a $90^{\circ}$, os jogadores realizavam três contrações máximas para cada velocidade. Seus achados revelaram que o pico de torque é inversamente proporcional à velocidade angular; que para quaisquer grupos musculares testados, o pico de torque não foi afetado pela dominância de membros, assim como a relação flexora/ extensora. Não houve nenhuma evidência de desequílibrios musculares nos grupos musculares e nas relações flexora/ extensora entre os jogadores com dominância em uma ou nos dois membros.

\subsection{Futebol de salão e treinamento físico}

Os jogos de futebol de salão são praticados em quadras de 25 a 42 metros (m) de comprimento e de 15 a 22 m de largura (Putukian et al., 1996). São permitidos 
cinco jogadores em quadra por equipe, sendo um goleiro e quatro jogadores de linha. A bola de jogo pode pesar de 400 a 440 gramas, e o tempo de jogo se divide em dois períodos de 20 minutos cronometrado com 10 minutos de intervalo entre ambos (FIFA, 2001).

Os fundamentos do futebol de salão são: domínio, passe, drible, chute, condução de bola e marcação. Consiste em domínio, a habilidade de recepção da bola em diferentes partes do corpo; passe é o meio de passar a bola entre elementos da mesma equipe, tendo como objetivo atingir a meta adversária; drible é o ato pelo qual se pode vencer um adversário através de toques sucessivos, mudanças de direção e deslocamento rápido, mantendo o domínio da bola e chute é o ato de golpear a bola, visando o gol ou de desviar a mesma, estando ela parada ou em movimentação. Condução de bola é a forma como o jogador progride com a bola no terreno de jogo. Marcação é a ação técnica que o jogador adquire de impedir que o adversário progrida ou receba a bola em condições de perigo ao seu gol (Júnior, 1999; Melo, 1999).

Para facilitar as adaptações biológicas e biomecânicas do atleta nos movimentos do esporte a realizar, de forma a aumentar seu rendimento e melhorar sua qualidade física, fazendo com que seja capaz de desempenhar a sua atividade esportiva da melhor maneira possível, tem-se o treinamento físico (Prati, 1992; Guyton e Hall, 1997; Mcardle et al., 1998).

O treinamento para a prática do futebol de salão exige:

- Condição física: desenvolvimento de velocidade, resistência, força, flexibilidade, coordenação dos movimentos, resistência cardiovascular e agilidade (Guillet et al., 1983; Becker Júnior e Samulki, 1998). 
- Condição técnica: aperfeiçoamento do gesto esportivo - coordenação dos fundamentos com um ritmo de execução semelhante ao da competição (Guillet et al., 1983; Becker Júnior e Samulki, 1998).

- Condição psíquica: aprendizagem do auto-controle e motivação durante todos os momentos do treinamento e competição (Guillet et al., 1983; Becker Júnior e Samulki, 1998).

- Organização tática: organização das relações entre os jogadores da equipe através de esquemas de jogos para alcançarem a vitória (Guillet et al., 1983; Becker Júnior e Samulki, 1998).

O treinamento é dividido em quatro fases (Mcardle et al., 1998):

- fase de preparação - treino de força baixa intensidade e treino aeróbico, anaeróbico e de flexibilidade;

- primeira transição - treino de força intensidade moderada e treinos específicos da prática esportiva;

- fase de competição - treino de força intensidade alta;

- segunda transição (repouso ativo) - ocorre no final da temporada e requer a manutenção da capacidade física do atleta.

Neste estudo, a fase de primeira transição é considerada como a fase pré temporada e a fase de competição é a fase de temporada.

A divisão do treinamento chama-se periodização e objetiva melhorar o desempenho dos atletas pela manipulação da intensidade, volume, freqüência, repetições e dos períodos de repouso durante o treinamento, que devem ser suficientes para permitir a recuperação do músculo sem sobrecarga excessiva. Tempo longo de descanso entre as sessões de atividade pode causar 
destreinamento, com reduções significativas na capacidade metabólica e do trabalho dos atletas. Estabelecer um programa de manutenção permanente, mesmo fora das temporadas de competição, a chamada fase de segunda transição, é importante para prevenção de perdas funcionais e lesões ME (Mcardle et al., 1998; Feigenbaum e Pollock, 1999).

O desempenho esportivo depende da hereditariedade e características individuais: antropometria, eficácia neurológica, capacidade cardiovascular, habilidade e força muscular (Araújo et al., 1996; Becker Júnior, 1998).

Segundo Júnior (1999), as aptidões físicas essenciais para a prática de futebol de salão são:

- resistência aeróbica: jogar o tempo total de jogo;

- resistência anaeróbica não lática para passes, chutes e piques de curta distância;

- resistência anaeróbica lática para as múltiplas repetições de alguns movimentos e intensidade de jogo;

- resistência muscular localizada para repetição dos gestos esportivos;

- potência (produto da força pela velocidade): necessária aos chutes e passes;

- ritmo: treinamento de resistência, força, velocidade, coordenação e flexibilidade;

- agilidade: capacidade física essencial no futebol de salão, devido aos espaços curtos de quadra, obrigando mudanças rápidas de direção;

- tempo de reação: respostas motrizes de ações rápidas;

- velocidade: para situações de contra- ataques;

- flexibilidade: garante melhores desempenhos (Júnior, 1999). 


\section{MÉTODOS}

\subsection{Análise da Casuística}

Este estudo foi aprovado em 13 de Abril de 2005, pela Comissão de Ética para Análise de projetos de Pesquisa, sob o código CAPPesq 982/04 (Anexo A). Todos os participantes assinaram um Termo de Consentimento Livre e Esclarecido (Anexo B), após os esclarecimentos que se fizeram necessários, previamente à análise dos critérios de inclusão.

Foram sujeitos deste estudo 92 jogadores de futebol de salão, do sexo masculino, praticantes do esporte há pelo menos dois anos, em treinamento técnico e tático de cinco vezes por semana (regularidade de treinamento aeróbico e anaeróbico) e participantes de equipes competitivas de três times de futebol de salão (Sport Clube Corinthians Paulista, Associação Desportiva São Caetano e São Paulo Futebol Clube).

Os critérios de inclusão:

- Ser jogador de futebol de salão federado;

- Jogadores com idade maior que 17 anos;

- Estar jogando e treinando regularmente;

- Ausência de lesão que tenha impedido treinamento ou jogo por pelo menos dois meses;

- Nenhum tipo de doença do aparelho locomotor;

- Nenhum tipo de doença pregressa; 
- Nenhuma deformidade anatômica;

- Não fazer uso de medicamentos ou drogas.

Os sujeitos foram selecionados da Federação Paulista de Futebol de Salão.

Foi realizado primeiramente um questionário adaptado de Baptista et al. (Ghorayeb e Barros, 1999) (Anexo C). Tal questionário inclui questões sobre posição de jogo, tempo de prática esportiva, tempo de treinamento, lesões prévias, uso de medicamentos e seqüelas persistentes. Esse questionário foi respondido pelos atletas e os dados foram utilizados para caracterizar a amostra estudada.

Os sujeitos foram avaliados por meio da dinamometria isocinética na pré temporada. A massa corporal e a estatura foram obtida antes da realização da

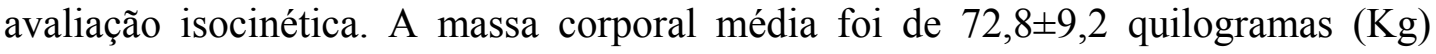
$(57,5$ a $101,2 \mathrm{Kg})$. A estatura média foi de $174,5 \pm 2,5$ centímetros $(\mathrm{cm})(160$ a 191,5 cm). A média de idade foi de 19,8 $\pm 6,5$ anos (17 a 33 anos).

O membro dominante foi definido com base no membro utilizado pelos jogadores nas suas habilidades motoras durante a prática esportiva, portanto o membro de mobilidade, aquele utilizado para o chute; enquanto o não dominante foi considerado o membro de suporte (Ergün et al., 2004). O membro dominante direito foi encontrado em 71 sujeitos $(77,2 \%)$ e o membro dominante esquerdo foi encontrado em 21 sujeitos (22,8\%). Na Tabela 1 encontram-se os dados antropométricos e identificação do membro dominante da amostra. 
Tabela 1 - Valores médios e desvio padrão dos dados antropométricos dos sujeitos e porcentagem de sujeitos com membro dominante direito e membro dominante esquerdo

\begin{tabular}{c|c}
\hline Idade (anos) $\mathrm{n}=92$ & $19,8 \pm 2,5$ anos \\
\hline Massa Pré Temporada $(\mathrm{Kg}) \mathrm{n}=92$ & $72,8 \pm 9,2 \mathrm{Kg}$ \\
\hline Massa Pós Temporada $(\mathrm{Kg}) \mathrm{n}=45$ & $71,4 \pm 7,8 \mathrm{Kg}$ \\
\hline Estatura $(\mathrm{cm}) \mathrm{n}=92$ & $174,9 \pm 6,4 \mathrm{~cm}$ \\
\hline Membro Dominante Direito $\mathrm{n}=92$ & $71(77,2 \%)$ \\
\hline Membro Dominante Esquerdo $\mathrm{n}=92$ & $21(22,8 \%)$ \\
\hline
\end{tabular}

Segundo a posição de jogo, 31,4\% dos sujeitos eram alas direita, 20,7\% fixos, $19,6 \%$ goleiros, $16,3 \%$ pivôs e $12 \%$ alas esquerda, conforme apresentado na Figura 2.

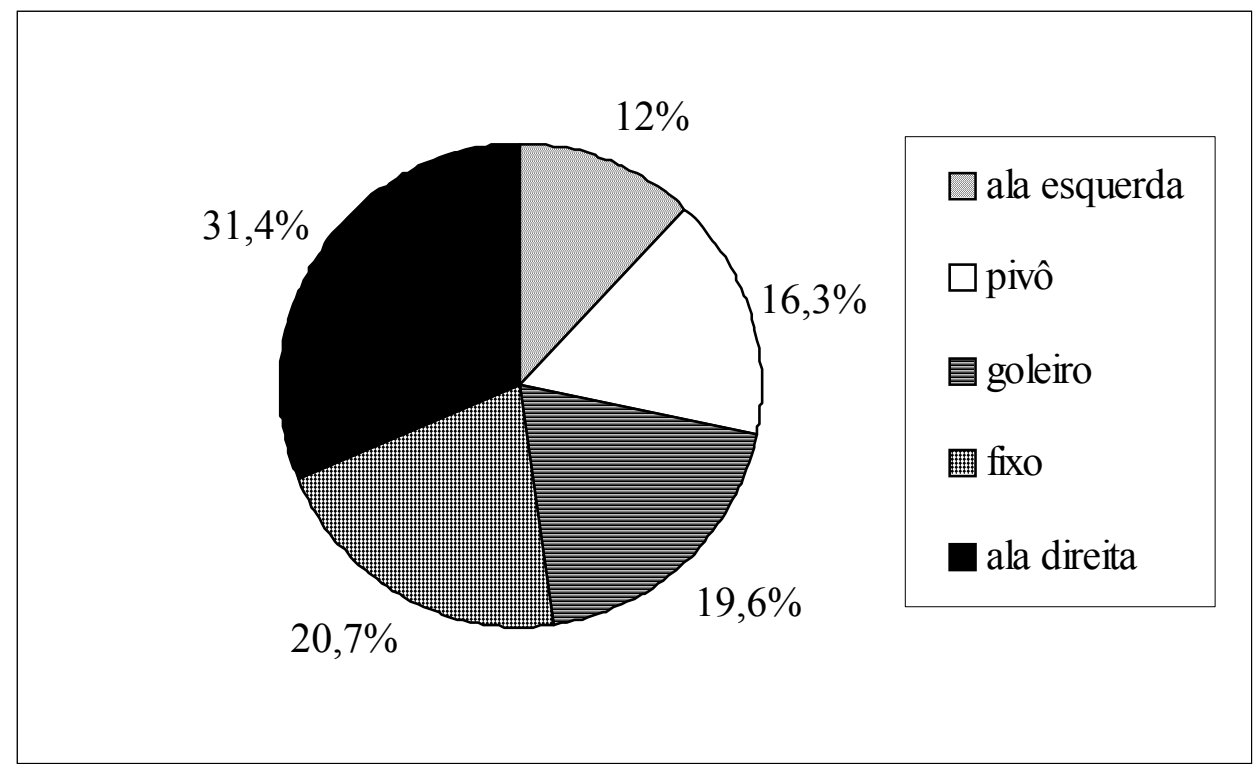

Figura 1 - Representação gráfica da porcentagem dos sujeitos segundo posição de jogo 


\subsection{Avaliação Clínica}

Após os atletas assinarem o Termo de Consentimento (Anexo B), serem incluídos no estudo e responderem o questionário (Anexo C) foi realizada a avaliação clínica dos sujeitos participantes, através da ficha de avaliação (Anexo D).

Os equipamentos utilizados foram: balança Welmy, fita métrica, bicicleta ergométrica Inbrasport- ATL- Brasil, dinamômetro isocinético da marca Cybex, modelo Norm.

Os atletas foram avaliados por um único avaliador, na clínica de fisioterapia da Universidade Cidade de São Paulo, com consentimento da Diretoria do Curso de Fisioterapia da Universidade Cidade de São Paulo (Anexo E). O avaliador era uma fisioterapeuta, habilitada para manuseio do dinamômetro isocinético.

\subsection{Dinamometria Isocinética}

As avaliações foram realizadas em um dinamômetro isocinético da marca Cybex, modelo Norm; da clínica de fisioterapia da Universidade Cidade de São Paulo, onde foram observados todos os cuidados necessários para um perfeito desempenho e sem nenhum risco de lesão para o atleta.

Os atletas realizaram cinco minutos de alongamento ativo de membros inferiores e cinco minutos de aquecimento na bicicleta ergométrica, sem carga, a 60 rotações por minuto (r.p.m). Os músculos alongados foram os do grupo flexor e 
extensor de quadril, rotadores mediais e laterais de quadril, adutores e abdutores de quadril, flexores e extensores de joelho, flexores dorsais e flexores plantares de tornozelo.

Antes do início do teste, o aparelho foi calibrado segundo normas do software da marca Cybex. Para este estudo foi selecionado o teste de extensão e flexão da articulação do joelho (Zakas et al., 1995; Akova et al., 1999; Cometti et al., 2001; Ergün et al. 2004, Zakas, 2006).

Após o alongamento e aquecimento, os sujeitos foram posicionados e foram feitos ajustes do dinamômetro para posicionamento e estabilização. Foram posicionados na posição sentada, com as costas reclinadas posteriormente a $80^{\circ}$ e as coxas apoiadas no acento com $90^{\circ}$ de flexão de quadril. $\mathrm{O}$ membro inferior a ser testado fixo na altura da coxa por uma cinta com velcro de estabilização. A articulação avaliada teve seu eixo de rotação (a linha lateral do joelho testado) alinhada com o eixo de rotação do aparelho, e o braço de alavanca do aparelho fixado em nível do maléolo medial. A amplitude de movimento partiu do zero graus (extensão total) a $90^{\circ}$ de flexão de joelho. O tronco foi fixado por um cinto de segurança próprio do dinamômetro, tendo os membros superiores lateralmente a uma alavanca, e o membro inferior não testado estabilizado em local próprio.

O teste foi realizado em duas seqüências de exercícios de contração concêntrica: $1^{\circ}$ : cinco repetições a $60^{\circ} / \mathrm{s}$, que avalia a força por meio do torque e $2^{\circ}$ : cinco repetições a $180^{\circ} / \mathrm{s}$, que avalia potência. Três repetições submáximas foram realizadas para adaptação à velocidade angular do teste e após estas repetições, os atletas foram orientados à série solicitada, com intervalos de 30 segundos para descanso entre a realização do movimento em cada velocidade e descanso de três 
minutos entre um membro e outro (Perrin, 1993; Dvir, 2002). Após o teste, os sujeitos realizaram novamente cinco minutos de alongamento. As avaliações foram realizadas na fase pré temporada em duas fases: pré temporada Fevereiro/Março de 2006 e pré temporada Fevereiro e Março de 2007.

Tanto a correção da força da gravidade, quanto a calibração do dinamômetro, seguiram a rotina proposta pelo software que gerencia o aparelho. A calibração do dinamômetro foi realizada a cada três avaliações completas.

Os atletas foram incentivados verbalmente antes e durante o teste, além de serem orientados visualmente pelos gráficos demonstrados no monitor do computador durante o teste para encorajamento para realizar o teste da melhor forma a cada repetição.

As variáveis analisadas foram torque máximo, trabalho total e relação flexora/ extensora. Todas as mensurações foram corrigidas pela massa corporal de cada sujeito e foram expressos em porcentagem de massa. A relação entre os grupos flexores e extensores foram feitas com base no pico de torque e trabalho total para as três velocidades. Comparações foram feitas segundo membro dominante e não dominante.

\subsection{Incidência das lesões}

A incidência das lesões foi coletada na fase de temporada de jogos (Março a Novembro) por meio de anotações do prontuário médico de cada atleta e por meio de acompanhamento de jogos e treinos feito pelo avaliador. Definiu-se como lesão 
musculoesquelética, aquela ocorrida nos jogos e treinamentos, de acordo com Mcmaster E Walter (1978), Sullivan et al. (1980), Pedrinelli (1994) e Cohen et al. (1997). Foram classificadas segundo a topografia: pé/ tornozelo, perna, joelho, coxa, quadril/ pelve, coluna e membros superiores.

Após a classificação por local, foi feita uma classificação em relação ao diagnóstico das lesões, que foram agrupadas em: lesões musculares, lesões tendíneas, lesões ligamentares, lesões articulares, contusões, fraturas, luxações e outras quando não se enquadrarem nessa classificação (Carazzato et al., 1992 Pedrinelli, 1994; Cohen el al., 1997; Cohen e Abdalla, 2002; Ribeiro et al., 2003).

Os sujeitos e os fisioterapeutas de cada clube eram contatados a cada três meses, para eliminar possíveis intercorrências que pudessem intervir na amostra estudada.

\subsection{Estatística}

Foram realizadas análise descritivas para estatura $(\mathrm{cm})$, idade (anos), massa corporal $(\mathrm{Kg})$ na pré temporada, membro dominante e posição de jogo.

Para as variáveis qualitativas (membro dominante, posição de jogo, presença ou não de lesão musculoesquelética) foi utilizado o teste não paramétrico de Igualdade de Duas Proporções.

Para comparar as variáveis quantitivas entre o membro dominante (MD) e membro não dominante (MND), foi utilizado o Teste de Wilcoxon, pois os dados possuem característica de pareamento. 
Para comparar as variáveis quantitativas com as qualitativas foi utilizado o teste de Kruskal-Wallis.

O nível de significância estabelecido foi de $5 \%(p<0,05)$ em todos os testes realizados. O software SPSS V11.5 foi utilizado para executar a análise estatística e os gráficos foram elaborados pelo programa Excel XP.

A análise foi realizada no aplicativo Minitab, versão 14 (Conover, 1971; Vieira, 1991; Murray, 1993; Marroco, 2003; Vieira, 2004). 


\section{RESULTADOS}

Os resultados do presente estudo estão separados de acordo com cada etapa e/ou fase do estudo, sendo assim: pré temporada e temporada.

\subsection{Fase Pré Temporada}

Tabela 2 - Valores médios, medianas, desvio padrão (DP) e p-valor das variáveis quantitativas dos músculos flexores e extensores de joelho do membro dominante $\mathrm{e}$ não dominante corrigidos pela massa corporal e expressos em porcentagem nas velocidades de $60 \%$ s e $180 \%$ s na pré temporada $(n=92)$

\begin{tabular}{|c|c|c|c|c|c|}
\hline \multicolumn{2}{|l|}{$\begin{array}{l}\text { Variáveis da pré temporada } \\
\qquad(\mathrm{n}=92)\end{array}$} & Médias & Medianas & $\begin{array}{l}\text { Desvio } \\
\text { Padrão }\end{array}$ & $\begin{array}{c}p- \\
\text { valor }\end{array}$ \\
\hline \multirow{2}{*}{ Pico de torque flexor a $60^{\circ} / \mathrm{s}$} & MD & 180,69 & 180,3 & 32,38 & \multirow{2}{*}{$0,017 *$} \\
\hline & MND & 174,69 & 173,1 & 31,46 & \\
\hline \multirow{2}{*}{ Pico de torque extensor a $60^{\circ} / \mathrm{s}$} & MD & 305,45 & 303,9 & 47,72 & \multirow{2}{*}{0,619} \\
\hline & MND & 307,52 & 308,2 & 47,28 & \\
\hline \multirow{2}{*}{ Trabalho total flexor a $60^{\circ} / \mathrm{s}$} & $\mathrm{MD}$ & 189,45 & 194,0 & 33,08 & \multirow{2}{*}{$0,011^{*}$} \\
\hline & MND & 181,94 & 183,4 & 33,63 & \\
\hline \multirow{2}{*}{ Trabalho total extensor a $60^{\circ} / \mathrm{s}$} & MD & 299,40 & 297,4 & 47,89 & \multirow{2}{*}{0,453} \\
\hline & MND & 297,27 & 290,4 & 50,65 & \\
\hline \multirow{2}{*}{ Trabalho total flexor a $180^{\circ} / \mathrm{s}$} & MD & 139,56 & 147,7 & 35,81 & \multirow{2}{*}{$<0,001 *$} \\
\hline & MND & 129,89 & 135,3 & 33,46 & \\
\hline \multirow{2}{*}{ Trabalho total extensor a $180^{\circ} / \mathrm{s}$} & MD & 227,95 & 227,6 & 36,28 & \multirow{2}{*}{0,258} \\
\hline & MND & 230,55 & 233,5 & 34,66 & \\
\hline \multirow{2}{*}{$\begin{array}{c}\text { Trabalho total flexor de todas as } \\
\text { repetições a } 60^{\circ} / \mathrm{s}\end{array}$} & MD & 616,36 & 622,0 & 138,11 & \multirow{2}{*}{$0,001 *$} \\
\hline & MND & 577,29 & 575,0 & 150,84 & \\
\hline \multirow{2}{*}{$\begin{array}{c}\text { Trabalho total flexor de todas as } \\
\text { repetições a } 180^{\circ} \mathrm{s}\end{array}$} & $\mathrm{MD}$ & 437,68 & 443,0 & 159,29 & \multirow{2}{*}{$0,001 *$} \\
\hline & MND & 397,90 & 421,0 & 149,94 & \\
\hline \multirow{2}{*}{$\begin{array}{c}\text { Trabalho total extensor de todas } \\
\text { as repetições a } 60^{\circ} / \mathrm{s}\end{array}$} & MD & 586,35 & 729,0 & 340,34 & \multirow{2}{*}{0,967} \\
\hline & MND & 592,35 & 730,0 & 339,67 & \\
\hline \multirow{2}{*}{$\begin{array}{l}\text { Trabalho total extensor de todas } \\
\text { as repetições a } 180^{\circ} / \mathrm{s}\end{array}$} & $\mathrm{MD}$ & 718,35 & 750,0 & 161,84 & \multirow{2}{*}{0,338} \\
\hline & MND & 726,79 & 749,0 & 177,24 & \\
\hline
\end{tabular}




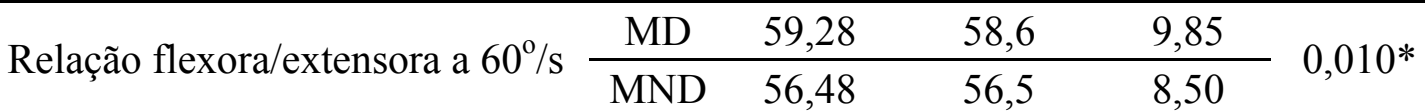

MD: membro dominante; MND: membro não dominante. Teste estatístico utilizado: Teste de Wilcoxon * diferença significante $(p<0,05)$

\subsection{Fase de Temporada}

Nesta fase foi realizada a coleta de lesões musculoesqueléticas sofridas pelos sujeitos, tanto em jogos oficiais como em treinamentos. Do total de sujeitos, 49 (53,3\%) sofreram lesão e $43(46,7 \%)$ não sofreram. Esta diferença não foi estatisticamente significante $(p=0,376)$.

Tabela 3 - Distribuição, porcentagem e p-valor das lesões musculoesqueléticas sofridas pelos sujeitos durante a temporada, segundo topografia

\begin{tabular}{lll}
\hline \multicolumn{1}{c}{ Local } & \% & p-valor \\
\hline TORNOZELO MD & $30,6 \%$ & 0 \\
\hline COXA MD & $16,3 \%$ & 0,095 \\
\hline JOELHO MD & $14,3 \%$ & 0,053 \\
\hline TORNOZELO MND & $14,3 \%$ & 0,053 \\
\hline COXA MND & $12,2 \%$ & $0,027^{*}$ \\
\hline JOELHO MND & $10,2 \%$ & $0,0128^{*}$ \\
\hline PÉ MD & $4,1 \%$ & $<0,001^{*}$ \\
\hline QUADRIL/PELVE & $4,1 \%$ & $<0,001^{*}$ \\
\hline COLUNA LOMBAR & $2,0 \%$ & $<0,001^{*}$ \\
\hline MÃO MD & $2,0 \%$ & $<0,001^{*}$ \\
\hline PÉ MND & $2,0 \%$ & $<0,001^{*}$ \\
\hline
\end{tabular}

MD: membro dominante; MND: membro não dominante. Teste Estatístico utilizado: Teste de Igualdade de Duas Proporções. * diferença significante $(p<0,05)$. 
Tabela 4 - Distribuição, porcentagem e p-valor das lesões musculoesqueléticas sofridas pelos sujeitos durante a temporada, segundo diagnóstico

\begin{tabular}{lcc}
\hline \multicolumn{1}{c}{ Diagnóstico } & \% & p-valor \\
\hline ARTICULAR & $46,9 \%$ & 0 \\
\hline MUSCULAR & $30,6 \%$ & 0,097 \\
\hline CONTUSÃO & $8,2 \%$ & $<0,001^{*}$ \\
\hline LIGAMENTAR & $6,1 \%$ & $<0,001^{*}$ \\
\hline OUTROS & $4,2 \%$ & $<0,001^{*}$ \\
\hline TENDÍNEA & $2,0 \%$ & $<0,001^{*}$ \\
\hline FRATURAS & $2,0 \%$ & $<0,001^{*}$ \\
\hline LUXAÇÕES & $0,0 \%$ & $<0,0018^{*}$ \\
\hline
\end{tabular}

Teste estatístico utilizado: Teste de Igualdade de Duas Proporções. * diferença significante $(p<0,05)$. 
Tabela 5 - Distribuição, porcentagem e p-valor das lesões musculoesqueléticas sofridas pelos sujeitos durante a temporada, segundo segmento tipo de lesão e topografia

\begin{tabular}{|c|c|c|}
\hline Lesão musculoesquelética & $\%$ & $p$-valor \\
\hline ENTORSE TORNOZELO MD & $30,6 \%$ & \\
\hline LESÃO MUSCULAR MD & $18,4 \%$ & 0,159 \\
\hline ENTORSE TORNOZELO MND & $14,3 \%$ & 0,053 \\
\hline ENTORSE JOELHO MD & $14,3 \%$ & 0,053 \\
\hline LESÃO MUSCULAR MND & $12,2 \%$ & $0,027^{*}$ \\
\hline ENTORSE JOELHO MND & $10,2 \%$ & $0,012 *$ \\
\hline CONTUSÃO MÃO MD & $4,1 \%$ & $<0,001 *$ \\
\hline PUBALGIA & $4,1 \%$ & $<0,001^{*}$ \\
\hline BURSITE QUADRIL MD & $2,0 \%$ & $<0,001 *$ \\
\hline CONTUSÃO PÉ MD & $2,0 \%$ & $<0,001 *$ \\
\hline CONTUSÃO PÉ MND & $2,0 \%$ & $<0,001 *$ \\
\hline LOMBALGIA & $2,0 \%$ & $<0,001 *$ \\
\hline TENDINITE CALCÂNEO MD & $2,0 \%$ & $<0,001 *$ \\
\hline TENDINITE CALCÂNEO MND & $2,0 \%$ & $<0,001 *$ \\
\hline
\end{tabular}

MD: membro dominante; MND: membro não dominante. Teste estatístico utilizado: Teste de Igualdade de Duas Proporções. * diferença significante $(p<0,05)$

Após a primeira análise do diagnóstico das lesões musculoesqueléticas, foi realizada uma segunda análise onde foi mais especificado o diagnóstico da lesão (Anexo F). 


\subsection{Correlações entre a avaliação isocinética e as lesões musculoesqueléticas}

Para se fazer as correlações entre as variáveis quantitativas da avaliação isocinética (categóricas) e a ocorrência de lesões, foram considerados somente os segmentos mais prevalentes em que as lesões musculoesqueléticas (ME) ocorreram, portanto: joelho MD, joelho MND, tornozelo MD, tornozelo MND, coxa MD e coxa MND. Para esta análise foi utilizado o teste de Kruskal-Wallis.

No Anexo G encontram-se os valores médios, medianas, desvio padrão (DP) e $p$-valor das variáveis quantitativas dos músculos flexores e extensores do joelho do membro dominante e não dominante na pré temporada dos 92 sujeitos. Não foram encontradas diferenças significantes entre as variáveis quantitativas para quaisquer das lesões ME ocorridas.

No Anexo H encontram-se os valores médios, medianas, desvio padrão (DP) e $p$-valor dos déficits dos músculos flexores e extensores do joelho do membro dominante e não dominante na pré temporada dos 92 sujeitos. Não foram encontradas diferenças significantes entre os déficits para quaisquer das lesões ME ocorridas. 


\section{DISCUSSÃO}

O aumento da prática de futebol de salão como lazer ou alto desempenho trouxe mais lesões do sistema músculoesquelético, que passaram a exigir maior atenção e cuidados dos profissionais de saúde. Algumas particularidades próprias do futebol de salão, como: tamanho da quadra, tipo de piso, demanda física, treinamento e outras interferem na incidência e tipo de lesões, vêm sendo cada vez mais estudadas, na busca de recursos de tratamento e prevenção.

No presente estudo, foram avaliados 92 atletas de futebol de salão, que realizaram uma avaliação isocinética dos músculos flexores e extensores do joelho, na fase pré temporada (janeiro e fevereiro de 2006 e 2007). Estes mesmos atletas foram acompanhados durante a temporada (jogos e treinamentos) de 2006 e 2007, para se verificar a incidência de lesões musculoesqueléticas (ME). Os atletas foram avaliados em duas velocidades (60\% segundo e $180^{\circ}$ /segundo). Foi realizada a avaliação isocinética do joelho utilizando-se como base a literatura científica, onde as lesões no joelho são as mais comuns na prática do futebol. Porém, isto não foi a realidade encontrada neste estudo com atletas de futebol de salão, onde predominaram as lesões no tornozelo.

A perda da função muscular pode estar relacionada com a ocorrência de lesão, assim como uma boa condição muscular pode ser um fator preventivo. A elaboração e a implementação dos programas de prevenção e melhora do desempenho esportivo, foi o motivo deste estudo, que analisou a correlação entre a função isocinética dos músculos flexores e extensores do joelho e a incidência de lesões musculoesqueléticas (ME) de membros inferiores. Definiu-se como 
lesão musculoesquelética, aquela ocorrida nos jogos ou treinamentos, de acordo com Mcmaster e Walter (1978), Sullivan et al. (1980), Pedrinelli (1994), Cohen et al. (1997).

A coleta de dados foi realizada unicamente pela autora através da análise dos prontuários médicos, acompanhamentos dos jogos e treinamentos, para evitar diferentes interpretações sobre conceito de lesão, localização anatômica e diagnóstico, de acordo com as recomendações de Carazzato et el. (1992), Lindenfeld et al. (1994), Junge e Dvorak (2000a).

A faixa etária da população estudada foi similar aos estudos de Lindenfeld et al., 1994; Cohen et al., 1997; Akova et al., 1999; Ergün et al., 2004; Newman et al., 2004; Gioftsidou et al., 2006, porém outros autores estudaram atletas mais velhos com idade média de 26 anos (Cometti et al.,2001; Stewien e Camargo, 2005 e Zakas, 2006). Porém a idade dos atletas não é um fator interferente na ocorrência das lesões ME. Diferenças fisiológicas influenciam na capacidade muscular, segundo Perrin (1993) e Dvir (2002) e por este motivo a casuística incluída neste estudo foi somente do sexo masculino.

Os membros inferiores foram acometidos em $91,8 \%$ das lesões. Este perfil foi encontrado na maioria dos estudos sobre o tema: 88\% (Ekstrand e Gillquist, 1983), 84\% (Nielsen e Johannes, 1989), Brynhildsen et al. (1990), 93\% (Engstrom et al., 1990), 84\% (Carazzato et al., 1992), 82,5\% (Pedrinelli, 1994), 63,5\% (Lindenfeld et al., 1994), 71,1\% (Putukian et al., 1996), 72,2\% (Cohen et al., 1997), Junge e Dvorak (2004).

O local mais acometido por lesão foi o tornozelo (44,9\%), seguido pela coxa (28,5\%) e joelho (24,5\%), achados estes compatíveis com Lindenfeld et al. (1994) e 
Putukian et al. (1996), que estudaram atletas de futebol de salão e Brynhildsen et al. (1990) e Junge e Dvorak (2000b), que estudaram futebol de campo.

O tornozelo foi articulação mais acometida, possivelmente porque os atletas não utilizavam proteção externa (enfaixamento ou bandagem elástica) nos treinamentos e jogos e também pela falta de exercícios profiláticos no programa de preparação física executado. Ekstrand et al. (1983) e Ekstrand e Nigg (1989) também observaram estas possíveis causas num grande número de lesões do tornozelo. Junge e Dvorak (2004) recomendam treinamento de propriocepção e coordenação para prevenir as entorses de tornozelo.

O diagnóstico mais comum foi entorse $(69,4 \%)$, seguido por lesão muscular (30,6\%). Os trabalhos de Ekstrand e Gillquist (1983), Nielsen e Johannes (1989), Brynhildsen et al. (1990), Engstrom et al. (1990), Carazzato et al. (1992), Putukian et al. (1996), Junge e Dvorak (2004), Ribeiro e Costa (2006) também mostraram uma grande freqüência de entorse de tornozelo nos seus trabalhos, mostrando que esta é uma das principais lesões do esporte e que medidas preventivas de treinamento, equipamentos de proteção e calçados adequados podem reduzir de forma muito significativa as lesões do esporte e melhorar o desempenho.

Pedrinelli (1994) e Ribeiro e Costa (2006), encontraram como diagnóstico mais freqüente a contusão, possivelmente, pelo tipo de disputa com grande contato corporal, facilitando este tipo de ocorrência pelos choques e quedas. Seria esperado, que em times mais bem orientados quanto ao preparo físico e uso de equipamentos de proteção do tornozelo, as contusões fossem mais comuns.

Lindenfeld et al. (1994) encontraram também as lesões ligamentares do joelho. A lesão do joelho também pode ocorrer pelo tipo de ação no esporte: explosão e 
parada, sendo que os mecanismos estabilizadores do joelho podem ser mais exigidos. Neste tipo de lesão, ações preventivas de reforço muscular, propriocepção e equilíbrio podem ser eficientes. Há dificuldades para se fazer a comparação direta entre os trabalhos publicados, pela heterogeneidade dos mesmos, com abordagens diversas e falta de informações sobre as equipes avaliadas: nível dos atletas e competições, preparo físico e equipamentos disponíveis. No entanto, de uma forma geral, as lesões do tornozelo são as mais freqüentes na maioria dos estudos com futebol de salão, mostrando que cuidados específicos com esta articulação precisam ser tomados no preparo físico e no uso de equipamentos de proteção. Lindenfeld et al. (1994) ressaltaram o fato de que o futebol de salão é diferente do futebol de campo pela área do campo, tipo de superfície, maior velocidade de jogo, número de faltas controladas, estilo mais agressivo e espaço relativamente pequeno. Estas diferenças fazem com que ocorram mais colisões que no futebol de campo, favorecendo a entorse de tornozelo.

As lesões musculares dos adutores do quadril, flexores do joelho e quadríceps foram o segundo diagnóstico mais freqüente. As lesões ocorreram nos membros dominantes e não dominantes, sem diferença. Cohen et al. (1997) encontraram lesões musculares como as mais freqüentes. A lesão muscular pode estar associada ao menor tamanho da quadra e necessidade de manobras mais difíceis para domínio e alcance da bola. Pode, também, estar associada à deficiência de aquecimento prévio e inadequação de treinamento e fortalecimento muscular.

O futebol de salão caracteriza-se por uma sucessão de movimentos de alta velocidade, com contínuas trocas de direção e sentido, intercalados com pausas, sobrecarregando a musculatura flexo - extensora do joelho. Há falta de exercícios de 
desaquecimento ou exercícios compensatórios após os treinamentos e jogos, que pode aumentar a retração da musculatura posterior da coxa, alterando o equilíbrio normal de torque entre flexores e extensores do joelho (flexores produzem de 60 a $65 \%$ de torque dos extensores, na velocidade de $60 \%$ s), segundo Ekstrand et al. (1983) e Dvir (2002).

As lesões musculoesqueléticas foram agrupadas pela ocorrência no membro dominante ou não dominante, para se fazer a correlação dos dados qualitativos (categóricos) com os dados quantitativos. Houve grande predomínio de sujeitos destros (77,2\%), achado semelhante aos de Ekstrand e Gillquist (1983), Pedrinelli (1994), Bennell et al. (1998), Akova et al. (1999), Zakas (2006), que está de acordo com distribuição normal da população em geral. Encontrou-se $30,6 \%$ de entorse no tornozelo dominante e $14,3 \%$ no não dominante, sem diferença significante. Este achado poderia ser esperado, pois a entorse pode ocorrer no chute (membro dominante e não dominante), na sucessão de movimentos de alta velocidade, característica do futebol de salão (ambos membros) e nas paradas com mudanças de direção (membro não dominante). Lindenfeld et al. (1994) e Medina et al. (2002) fazem referência a esta ocorrência de lesões sem relação com a dominância. A grande habilidade exigida para a prática do esporte exige dos dois membros inferiores e pode estar implicada no equilíbrio das lesões.

A dominância de membro, no entanto, pode influenciar nos valores dos parâmetros isocinéticos e por este motivo os resultados foram analisados separadamente de acordo com a dominância. Goslin e Charteris (1979); Akova et al. (1999); Terreri et al. (2001); Siqueira et al. (2002); Ergün et al (2004) e Zakas, 
(2006) recomendam que a análise das variáveis medidas na dinamometria isocinética seja feita de acordo com a dominância do membro.

As variáveis pico de torque e trabalho total, obtidas na dinamometria isocinética e utilizadas neste estudo, foram normalizadas pela massa corporal e expressas em valores de porcentagem, para homogeneização do grupo (Greve, 2007). A massa corporal média da população estudada $(71,2 \mathrm{~kg})$ foi semelhante a de outros estudos (Zakas et al. 1995; Akova et al., 1999; Cometti et al., 2001; Ergün et al., 2004; Magalhães, 2004). Alguns estudos, porém mostram massa corporal média acima de 80 kg (Bennell et al., 1998; Newman et al., 2004 e Zakas, 2006), mostrando que o biotipo do atleta de futebol de salão, assim como do futebol é mais variado que de outros esportes (basquetebol e voleibol), nos quais a habilidade e controle motor são mais importantes.

$\mathrm{O}$ perímetro da coxa está relacionado freqüentemente à força muscular do membro inferior, no entanto, a associação entre perimetria de membros inferiores e a produção de torque é questionada, pois ela pode não indicar especificamente alterações na produção do torque muscular (Alison et al., 1993). Neste estudo, apesar de termos verificado a perimetria dos membros inferiores, não foi feita correlação com o torque e trabalho muscular gerado no joelho.

A avaliação da função muscular, na fase pré temporada, é muito importante para fornecer subsídios de treinamento: correção dos desequilíbrios encontrados, adequação do preparo físico e melhora da condição física de forma geral para garantir o desempenho e evitar lesões.

$\mathrm{Na}$ fase pré temporada, os sujeitos apresentaram os músculos flexores do joelho do membro não dominante mais fracos que os do membro dominante, fato este que 
pode ser explicado pela definição de dominância, já que o membro não dominante é o membro de suporte. A maior atividade dos flexores do joelho no membro dominante também pode ser relacionada com o chute, possivelmente, pela ação excêntrica na desaceleração do movimento após o toque do pé na bola. Zakas et al. (1995), Akova et al. (1999), Ergün et al. (2004) mostraram resultados semelhantes, mas Zakas, em trabalho de 2006 mostrou que não há diferenças entre os lados na dinamometria isocinética.

Na pré temporada (Tabela 2) houve diferença entre o membro dominante e não dominante nas variáveis: pico de torque flexor a $60^{\circ} / \mathrm{s}$, trabalho flexor da melhor repetição nas velocidades de $60^{\circ} / \mathrm{s}$ e $180 \%$ s e na soma de todas as repetições dos flexores (trabalho total de todas as repetições) na velocidade de $60^{\circ} / \mathrm{s}$ e $180 \%$ s. A perda relativa da atividade flexora pode ser explicada pela falta de treinamento muscular específico durante o período de inatividade e férias e atividade específica do chute no lado dominante.

A entorse de tornozelo e a entorse do joelho, no entanto, acometeram os dois lados, independentemente da dominância, mostrando que a fraqueza relativa dos flexores do joelho do lado não dominante não contribuiu para aumentar a freqüência destas lesões. Também não foram observadas mais lesões no lado não dominante, mostrando que a perda relativa da atividade flexora deste lado, por si só, não se relaciona com maior incidência de lesões.

Ainda na pré temporada, a relação flexora/extensora na velocidade de $60 \%$ foi desfavorável em ambos lados, mostrando que havia uma fraqueza relativa dos flexores. Este desequilíbrio foi ainda maior do lado não dominante. Não houve diferenças na ocorrência de entorse de tornozelo e joelho em relação à dominância, podendo 
sugerir que a assimetria entre os flexores e extensores seria mais importante na gênese das lesões que a assimetria entre os lados dominante e não dominante. Os músculos flexores e extensores do joelho auxiliam a ação estabilizadora dos ligamentos cruzados anteriores na estabilização anterior do joelho e a diminuição da sua ação muscular pode contribuir para a maior instabilidade da articulação e favorecer lesões (Akova et al., 1999; Cometti et al., 2001; Ergün et al., 2004; Magalhães et al., 2004).

A relação flexora/extensora, obtida na dinamometria isocinética, é um indicador de equílibrio entre a função dos extensores e dos flexores no joelho (Dvir, 2002; Gioftsidou et al., 2006). Na velocidade de $60^{\circ}$ s, valores menores que $61 \%$ de relação flexora/ extensora aumentam o risco para lesões dos cruzados anteriores durante a temporada de jogos e treinamentos, segundo Perrin (1993), Bennell et al. (1998), Magalhães (2004) e Zakas (2006).

Nas lesões musculares, também, não foram observadas diferenças de ocorrência entre os lados dominante e não dominante, com exceção da lesão dos músculos flexores do joelho, que só ocorreu do lado dominante e que poderia estar relacionada com a perda relativa de ação destes músculos, com falha de ação excêntrica durante o chute, mas o número de ocorrências foi pequeno, impedindo uma avaliação mais consistente.

No futebol, o grupo muscular extensor é fundamental no chute, saltos, passes e dribles, enquanto o grupo muscular flexor controla o joelho nas atividades de corrida e age como estabilizador nos giros e paradas (Akova et al.,1999; Cometti et al., 2001; Magalhães et al.. 2004; Kalapotharakos et al.. 2006). Seria esperado, que o desequilíbrio da atividade dos flexores causasse maior número de lesões relacionadas 
com a estabilidade articular (entorse e lesões ligamentares), principalmente no membro inferior não dominante, mas esta relação direta não foi observada.

Hagood et al. (1990) referiram que os músculos flexores do joelho e o músculo quadríceps têm aumento na co-ativação do antagonista durante os últimos $40^{\circ}$ de extensão e na flexão, nos movimentos de alta velocidade, e este mecanismo é muito importante para assegurar a estabilidade articular. Este fato poderia estar associado com o melhor desempenho extensor do lado não dominante, porém, o mais provavél é que seja o desuso da fase pré temporada, que leve à menor ação dos flexores do joelho. Dvir (2002) refere que as velocidades mais altas, na dinamometria isocinética, não proporcionam informação útil para as avaliações no joelho, a não ser que houvesse uma boa razão para acreditar que a deficiência principal estaria associada com desempenho muscular a alta velocidade.

Para comparar as variáveis isocinéticas com as lesões musculoesqueléticas, na pré temporada foi utilizado o teste de Kruskal-Wallis. Não foram encontradas correlações estatisticamente significantes entre as lesões musculoesqueléticas e as variáveis isocinéticas. Foi constatada, através da avaliação isocinética na pré temporada, a fraqueza dos músculos flexores do joelho, porém as lesões musculoesqueléticas que ocorreram não se relacionaram com este desequilíbrio, isto é, as lesões estão, possivelmente, mais relacionadas com o mecanismo de trauma do que com as alterações estruturais e funcionais.

Terreri et al. (2001) afirmam a importância da avaliação isocinética em fornecer dados quantificados de forma objetiva, facilitando e orientando o trabalho de reequílibrio muscular para a prática da atividade esportiva. A avaliação isocinética 
dos joelhos, no futebol de salão, é importante para melhorar o treinamento dos atletas, mas não estaria, diretamente associada à entorse de tornozelo.

Neste estudo a falta de condição muscular não pode ser responsabilizada pelo grande número de entorses, ainda a fadiga muscular poderia causar a lesão. Assim, a avaliação utlizada, dinamometria isocinética do joelho, não foi adequada e possivelmente, outras avaliações poderiam ser mais eficazes para avaliar os riscos de entrose de tornozelo.

A dinamometria isocinética dos músculos dos pés e tornozelos associada à avaliação cinética e cinemática da articulação poderiam ser mais efetivas para a detecção de desequilíbrios e para orientação de programas de treinamento voltados para a prevenção deste tipo de lesão. Há necessidade de mais trabalhos, que gerem mais informações sobre o futebol de salão, que pelas suas particularidades, não pode ser comparado de forma direta com os dados e conhecimentos obtidos do futebol de campo. Este trabalho mostrou, que ainda que haja semelhanças com o futebol de campo, as diferenças também são importantes. A lesão do tornozelo é a lesão mais prevalente no futebol de salão e há muita necessidade de mais pesquisas e conhecimentos sobre os mecanismos de lesão, fatores de risco e prevenção para melhorar a segurança e desempenho dos atletas de futebol de salão. 


\section{CONCLUSÕES}

- Há fraqueza relativa dos músculos flexores do joelho em relação aos extensores e esta fraqueza é mais evidente no membro inferior não dominante de apoio.

- A localização mais freqüente das lesões é nos membros inferiores, o local mais acometido foi o tornozelo e o dignóstico mais comum foi entorse, sem relação com a dominância dos membros inferiores.

- Não houve correlação entre as variáveis isocinéticas e as lesões musculoesqueléticas dos membros inferiores. 


\section{ANEXOS}

Anexo A - Comissão de Ética

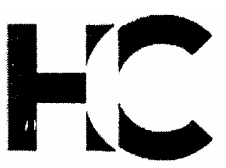

\section{APROVAÇÃO}

A Comissão de Ética para Análise de Projetos de Pesquisa - CAPPesq da Diretoria Clínica do Hospital das Clínicas e da Faculdade de Medicina da Universidade de São Paulo, em sessão de 13.04.05, APROVOU o Protocolo de Pesquisa $n^{\circ}$ 982/04, intitulado: "Incidência de lesões músculo-esqueléticas dos membros inferiores em atletas de futebol de salão e sua relação com a dinamometria isocinética em pré e pós temporada" apresentado pelo Departamento de ORTOPEDIA E TRAUMATOLOGIA, inclusive o Termo de Consentimento Livre e Esclarecido.

Cabe ao pesquisador elaborar e apresentar à CAPPesq, os relatórios parciais e final sobre a pesquisa (Resolução do Conselho Nacional de Saúde $n^{\circ} 196$, de 10.10.1996, inciso IX.2, letra " $c$ ").

Pesquisador(a) Responsável: Profa. Dra. Júlia Maria D’Andrea Greve Pesquisador(a) Executante: Sra. Nataly Vasconcellos Santos de Andrade CAPPesq, 13 de Abril de 2005

$$
\text { luth Cosillo }
$$

PROF. DR. EUCLIDES AYRES DE CASTILHO Presidente da Comissão de Ética para Análise de Projetos de Pesquisa

Comissão de Ética para Análise de Projetos de Pesquisa do HCFMUSP e da FMUSP Diretoria Clínica do Hospital das Clínicas da Faculdade de Medicina da Universidade de São Paulo Rua Ovidio Pires de Campos. 225, $5^{\circ}$ andar - CEP 05403010 - São Paulo - SP 
Anexo B - Termo de Consentimento Livre e Esclarecido

HOSPITAL DAS CLÍNICAS

DA

FACULDADE DE MEDICINA DA UNIVERSIDADE DE SÃO PAULO

TERMO DE CONSENTIMENTO LIVRE E ESCLARECIDO

(Instruções para preenchimento no verso)

\section{I - DADOS DE IDENTIFICAÇÃO DO SUJEITO DA PESQUISA OU RESPONSÁVEL LEGAL}

1. NOME DO PACIENTE.

DOCUMENTO DE IDENTIDADE ${ }^{\circ}$ : SEXO : .M F

DATA NASCIMENTO:

$\mathrm{N}^{\mathrm{o}}$

APTO

ENDEREÇO CIDADE

BAIRRO:

CEP:

TELEFONE: DDD .)

\section{RESPONSÁVEL LEGAL}

NATUREZA (grau de parentesco, tutor, curador etc.)

DOCUMENTO DE IDENTIDADE : SEXO: $\mathrm{M} \quad \mathrm{F}$

DATA NASCIMENTO.: .....................

ENDEREÇO: $\mathrm{N}^{\mathrm{o}}$ APTO:

BAIRRO: CIDADE

CEP: TELEFONE: DDD

\section{II - DADOS SOBRE A PESQUISA CIENTÍFICA}

1. TÍTULO DO PROTOCOLO DE PESQUISA: Incidência de lesões músculo- esqueléticas dos membros inferiores em atletas de futebol de salão e sua relação com a dinamometria isocinética em pré e pós temporada.

PESQUISADOR: Profa. Dra. Júlia Maria D’ Andrea Greve

CARGO/FUNÇÃO: Médica

INSCRIÇÃO CONSELHO REGIONAL No CRM: 26.970

UNIDADE DO HCFMUSP: Médica e Professora associada do Departamento de Ortopedia e Traumatologia FMUSP, orientadora pós graduação Disciplina Fisiopatologia Experimental FMUSP.

2. AVALIAÇÃO DO RISCO DA PESQUISA:

$\begin{array}{llll}\text { SEM RISCO } & \text { RISCO MÍNIMO } & \mathrm{X} & \text { RISCO MÉDIO } \\ \text { RISCO BAIXO } & \text { RISCO MAIOR } & \end{array}$

(probabilidade de que o indivíduo sofra algum dano como consequência imediata ou tardia do estudo)

3.DURAÇÃO DA PESQUISA : 18 meses 


\section{III - REGISTRO DAS EXPLICAÇÕES DO PESQUISADOR AO PACIENTE OU SEU REPRESENTANTE LEGAL SOBRE A PESQUISA, CONSIGNANDO:}

1. justificativa e os objetivos da pesquisa;

O Sr. é jogador de futebol de salão e realiza treinamento intensivo e repetitivo desta modalidade esportiva, a qual proporciona aumento da massa muscular (hipertrofia), porém podem ser causadas lesões decorrentes da prática esportiva. As lesões que predominam em jogadores de futebol de salão ocorrem em membros inferiores, com maior predomínio nos joelhos. Sendo assim o objetivo da pesquisa é verificar o número de lesões de membros inferiores (incidência) em jogadores de futebol de salão e sua relação com a força muscular dos membros inferiores.

2. procedimentos que serão utilizados e propósitos, incluindo a identificação dos procedimentos que são experimentais;

Para realizar esta pesquisa o Sr. deverá responder a um questionário para que sejam coletados dados sobre sua prática esportiva. Após o Questionário, o Sr. passará por uma Avaliação Clínica, onde serão coletados dados simples como peso, altura, idade, gordura corporal, tamanho dos membros inferiores e massa muscular. Para colhermos dados de sua força muscular, o Sr. passará por um teste que se chama Dinamometria Isocinética antes da fase competitiva e após a fase competitiva. Será de exercícios, sendo que a primeira terá 5 repetições e será destinada para captar dados de força muscular e a segunda de 20 repetições para captar dados de resistência muscular. Antes do teste o Sr. realizará 5 minutos de alongamento e 5 minutos de aquecimento na bicicleta ergométrica a 60 rotações por minuto (r.p.m.) $\mathrm{O}$ Sr. será orientado verbalmente antes e durante o teste, além de ser orientado pelos gráficos no computador. Durante o período competitivo o Sr. atualizará o questionário para fazermos um levantamento do número de lesões que o Sr. poderá sofrer. O propósito deste estudo é verificar se há relação entre o número de lesões que o Sr. e os outros jogadores poderão apresentar na fase de competição com os resultados de força muscular e resistência

3. desconfortos e riscos esperados;

Este aparelho, o Dinamômetro isocinético permite que o risco de lesão seja quase nulo, garantindo assim segurança para o Sr. Há estudos que afirmam que este método é o mais seguro em termos de avaliação músculo- esquelética. $\mathrm{O}$ aparelho será ajustado para cada avaliação para que o Sr. tenha maior segurança e conforto durante a realização do teste. Como é um teste que exige esforço máximo, o Sr. deve alimentar-se adequadamente antes do teste. 
4. benefícios que poderão ser obtidos;

benefícios da pesquisa são: com os dados da dinamometria isocinética e com o levantamento da incidência de lesões, serão identificados fatores de risco na prática do futebol de salão, poderão ser elaborados futuros programas de prevenções de lesões e o Sr. poderá ser encaminhado para os serviços de reabilitação, caso haja necessidade.

5. procedimentos alternativos que possam ser vantajosos para o indivíduo.

Durante o período competitivo e pós competitivo, o Sr. deverá ser submetido a tratamento na fisioterapia da Universidade Cidade de São Paulo caso sofra alguma lesão e terá disponibilidade de assistência no Departamento de Fisiatria do Instituto de Ortopedia e Traumatologia do Hospital das Clínicas da FMUSP (HCFMUSP) por eventuais danos à saúde, decorrentes da pesquisa.

\section{IV - ESCLARECIMENTOS DADOS PELO PESQUISADOR SOBRE}

\section{GARANTIAS DO SUJEITO DA PESQUISA:}

1. acesso, a qualquer tempo, às informações sobre procedimentos, riscos e benefícios relacionados à pesquisa, inclusive para dirimir eventuais dúvidas

O Sr. terá acesso a qualquer tempo às informações sobre procedimentos, riscos e benefícios relacionados a esta pesquisa, além do fornecimento dos dados para o Sr., para a Equipe Médica ou para o serviço responsável. Qualquer esclarecimento adicional sobre a pesquisa será fornecido pelos membros do Departamento de Fisiatria do Instituto de Ortopedia e Traumatologia do Hospital das Clínicas da FMUSP.

2. liberdade de retirar seu consentimento a qualquer momento e de deixar de participar do estudo, sem que isto traga prejuízo à continuidade da assistência.

A qualquer momento o Sr. poderá retirar seu consentimento e deixar de participar deste estudo sem haver qualquer prejuízo na continuidade de seu tratamento, caso o esteja realizando.

3. salvaguarda da confidencialidade, sigilo e privacidade:

Todos os dados serão utilizados exclusivamente para esta pesquisa e garantimos sua confidencialidade, sigilo e privacidade do seu nome, informamos ainda, que a sua participação no estudo estará ajudando no avanço e progresso da ciência, da medicina

4. disponibilidade de assistência no HCFMUSP, por eventuais danos à saúde, decorrentes da pesquisa. 
Durante o período competitivo e pós competitivo, o Sr. deverá ser submetido a tratamento na fisioterapia da Universidade Cidade de São Paulo caso sofra alguma lesão e terá disponibilidade de assistência no Departamento de Fisiatria do Instituto de Ortopedia e Traumatologia do Hospital das Clínicas da FMUSP (HCFMUSP) por eventuais danos à saúde, decorrentes da pesquisa.

5. viabilidade de indenização por eventuais danos à saúde decorrentes da pesquisa.

Há viabilidade de indenização por eventuais danos à saúde decorrentes da pesquisa,

\section{INFORMAÇÕES DE NOMES, ENDEREÇOS E TELEFONES DOS RESPONSÁVEIS PELO ACOMPANHAMENTO DA PESQUISA, PARA CONTATO EM CASO DE INTERCORRÊNCIAS CLÍNICAS E REAÇÕES ADVERSAS.}

- Júlia Maria D'Andrea Greve

Endereço: Rua Dr. Ovídeo Pirres de Campos, 333 Cerqueira César/ SP

Telefones: 3069.6423 e 9872.6665

- Nataly Vasconcellos Santos de Andrade

Endereço: Rua Cesário Galeno, 448

Telefones: 6190.1297 e 9790.6343

\section{OBSERVAÇÕES COMPLEMENTARES:}

\section{VII - CONSENTIMENTO PÓS-ESCLARECIDO}

Declaro que, após convenientemente esclarecido pelo pesquisador e ter entendido o que me foi explicado, consinto em participar do presente Protocolo de Pesquisa

São Paulo,

de de $200 \ldots$. 


\section{Anexo C - Questionário}

\section{Questionário}

Nome:

Posição de jogo: ( ) GOLEIRO

( ) BEQUE FIXO

( ) ALA DIREITA

( ) ALA ESQUERDA

( ) PIVÔ

É jogador federado? ( ) SIM ( )NÃO

Clube em que joga?

Tempo que pratica futebol de salão?

Treina quantas vezes por semana?

Treina quantas horas por dia?

Pratica musculação?

( ) SIM ( ) NÃO

Se sim, quantas vezes por semana e quantas horas por dia

Realiza outra prática esportiva? ( ) SIM ( ) NÃO

Já sofreu alguma lesão? （） SIM （）NÃO

Qual a região do corpo foi afetada?

Há quanto tempo ocorreu a última lesão?

Quanto tempo ficou parado devido a lesão?

Realizou algum tipo de tratamento?(medicamentos, cirurgia ou fisioterapia):

Tem doenças crônicas ou malformações congênitas?

Recentemente sofreu cirurgia ou hospitalização?

Faz uso de medicações? Quais?

Faz uso de medicamentos ou substâncias para aumento ou perda de peso, ou para melhorar o desempenho físico?

Faz ou fez uso de drogas, fumo ou bebidas alcoólicas?

Já apresentou manifestações alérgicas durante ou após exercício?

Tem necessidade de ganhar ou perder peso, devido à modalidade esportiva?

É suscetível a infecções freqüentes?

Teve infecção viral recentemente? 
Já apresentou paralisias, sensação de formigamento, anestesia em membros superiores ou inferiores?

Já apresentou crises de asma e/ou falta de ar durante ou após o exercício?

Já teve desmaio, vertigem, tontura durante o exercício?

Tem dores nas panturrilhas durante o exercício?

Alguma vez já foi proibido por motivo médico de participar em esportes devido a problema cardíaco?

Utiliza algum protetor para sua modalidade esportiva?

Data:

Telefone para contato: 


\section{Anexo D - Ficha de Avaliação}

\section{Ficha de Avaliação}

- Nome Completo:

- Idade: anos. Peso: $\mathrm{Kg}$.

Altura: $\mathrm{cm}$

- Membro Dominante:

- Perimetria de membros Inferiores:

Membro inferior D Membro inferior E

- Discrepância de Membros Inferiores:

Direito Esquerdo

Real

Aparente

- Inspeção:

- Palpação: 


\section{Anexo E - Carta de autorização}

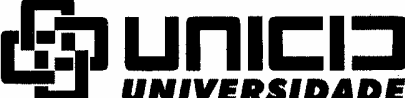

Declaro que a fisioterapeuta Nataly Vasconcellos Santos de Andrade, RG:30789456.3 e CREFITO: 3/41462-F, está autorizada a realizar a Avaliação Isocinética na Clínica de Fisioterapia da Universidade Cidade de São Paulo, para o Projeto de Pesquisa de Mestrado "Incidência de lesões músculo-esqueléticas em membros inferiores em atletas de futebol de salão e sua relação com a dinamometria isocinética em pré e pós temporada" 
Anexo F - Distribuição, porcentagem e p-valor das lesões musculoesqueléticas sofridas pelos sujeitos durante a temporada, segundo local, diagnóstico e estrutura comprometida de acordo com a dominância de membros

\begin{tabular}{|c|c|c|c|}
\hline Lesão musculoesquelética & Quantidade & $\%$ & $p$-valor \\
\hline ENTORSE TORNOZELO MD & 15 & $30,6 \%$ & 0 \\
\hline ENTORSE TORNOZELO MND & 7 & $14,3 \%$ & 0,053 \\
\hline ENTORSE JOELHO MD & 4 & $8,2 \%$ & $0,005^{*}$ \\
\hline ENTORSE JOELHO MND & 4 & $8,2 \%$ & $0,005^{*}$ \\
\hline ESTIRAMENTO ADUTOR MD & 4 & $8,2 \%$ & $0,005^{*}$ \\
\hline ESTIRAMENTO ADUTOR MND & 4 & $8,2 \%$ & $0,005^{*}$ \\
\hline ESTIRAMENTO FLEXORES JOELHO MD & 3 & $6,1 \%$ & $0,002 *$ \\
\hline $\begin{array}{l}\text { LESÃO LIGAMENTO COLATERAL MEDIAL } \\
\text { JOELHO MD }\end{array}$ & 3 & $6,1 \%$ & $0,002 *$ \\
\hline CONTUSÃO MÃO MD & 2 & $4,1 \%$ & $<0,001^{*}$ \\
\hline ESTIRAMENTO QUADRICEPS MD & 2 & $4,1 \%$ & $<0,001^{*}$ \\
\hline ESTIRAMENTO QUADRÍCEPS MND & 2 & $4,1 \%$ & $<0,001^{*}$ \\
\hline PUBALGIA & 2 & $4,1 \%$ & $<0,001 *$ \\
\hline BURSITE QUADRIL MD & 1 & $2,0 \%$ & $<0,001 *$ \\
\hline CONTUSÃO PÉ MD & 1 & $2,0 \%$ & $<0,001 *$ \\
\hline CONTUSÃO PÉ MND & 1 & $2,0 \%$ & $<0,001 *$ \\
\hline LESÃO MENISCO MND & 1 & $2,0 \%$ & $<0,001^{*}$ \\
\hline LOMBALGIA & 1 & $2,0 \%$ & $<0,001 *$ \\
\hline TENDINITE CALCÂNEO MD & 1 & $2,0 \%$ & $<0,001^{*}$ \\
\hline TENDINITE CALCÂNEO MND & 1 & $2,0 \%$ & $<0,001^{*}$ \\
\hline
\end{tabular}

Legenda: MD: membro dominante e MND: membro não dominante. Teste estatístico utilizado: Teste de Igualdade de Duas Proporções. *diferença significante $(\mathrm{p}<0,05)$. 
Anexo G - Valores médios, medianas, desvio padrão (DP) e p-valor das variáveis quantitativas dos músculos flexores e extensores do joelho do membro dominante e não dominante corrigidos pela massa corporal e expressos em porcentagem nas velocidades de $60^{\circ} / \mathrm{s}$ e $180 \%$ s na pré temporada dos 92 sujeitos, segundo as lesões músculo esqueléticas mais prevalentes

\begin{tabular}{|c|c|c|c|c|c|}
\hline Variáveis da pré & mporada (n=92) & Médias & Medianas & $\begin{array}{c}\text { Desvio } \\
\text { Padrão } \\
\end{array}$ & $p$-valor \\
\hline \multirow{6}{*}{$\begin{array}{c}\text { Pico de torque } \\
\text { flexor a } 60^{\circ} / \mathrm{s} \text { do } \\
\text { membro } \\
\text { dominante }\end{array}$} & Coxa MD & 182,8 & 183,8 & 32,2 & \multirow{6}{*}{0,651} \\
\hline & Coxa MND & 186,1 & 186,3 & 28,4 & \\
\hline & Joelho MD & 164,0 & 169,7 & 27,0 & \\
\hline & Joelho MND & 187,0 & 184,4 & 10,3 & \\
\hline & Tornozelo MD & 182,1 & 174,4 & 35,2 & \\
\hline & Tornozelo MND & 188,0 & 196,8 & 31,9 & \\
\hline \multirow{6}{*}{$\begin{array}{l}\text { Pico de torque } \\
\text { flexor a } 60^{\circ} / \mathrm{s} \text { do } \\
\text { membro não } \\
\text { dominante }\end{array}$} & Coxa MD & 181,0 & 192,6 & 29,6 & \multirow{6}{*}{0,232} \\
\hline & Coxa MND & 187,3 & 185,5 & 26,9 & \\
\hline & Joelho MD & 158,0 & 169,7 & 32,2 & \\
\hline & Joelho MND & 190,2 & 187,5 & 14,3 & \\
\hline & Tornozelo MD & 164,6 & 168,6 & 33,0 & \\
\hline & Tornozelo MND & 188,6 & 189,4 & 19,0 & \\
\hline \multirow{6}{*}{$\begin{array}{l}\text { Pico de torque } \\
\text { extensor a } 60^{\circ} / \mathrm{s} \\
\text { do membro } \\
\text { dominante }\end{array}$} & Coxa MD & 304,6 & 296,0 & 39,4 & \multirow{6}{*}{0,882} \\
\hline & Coxa MND & 305,9 & 308,3 & 35,1 & \\
\hline & Joelho MD & 290,3 & 276,5 & 62,6 & \\
\hline & Joelho MND & 314,1 & 324,6 & 35,5 & \\
\hline & Tornozelo MD & 312,0 & 297,6 & 34,0 & \\
\hline & Tornozelo MND & 308,5 & 327,3 & 25,1 & \\
\hline \multirow{6}{*}{$\begin{array}{l}\text { Pico de torque } \\
\text { extensor a } 60^{\circ} / \mathrm{s} \\
\text { do membro não } \\
\text { dominante }\end{array}$} & Coxa MD & 312,8 & 303,2 & 42,5 & \multirow{6}{*}{0,845} \\
\hline & Coxa MND & 325,3 & 312,3 & 64,8 & \\
\hline & Joelho MD & 306,6 & 294,3 & 39,4 & \\
\hline & Joelho MND & 321,5 & 307,9 & 63,5 & \\
\hline & Tornozelo MD & 305,2 & 300,0 & 54,0 & \\
\hline & Tornozelo MND & 330,8 & 339,0 & 27,8 & \\
\hline \multirow{6}{*}{$\begin{array}{l}\text { Trabalho total } \\
\text { flexor a } 60^{\circ} / \mathrm{s} \text { do } \\
\text { membro } \\
\text { dominante }\end{array}$} & Coxa MD & 197,8 & 199,3 & 30,4 & \multirow{6}{*}{0,935} \\
\hline & Coxa MND & 198,6 & 202,7 & 31,5 & \\
\hline & Joelho MD & 181,5 & 185,4 & 31,9 & \\
\hline & Joelho MND & 190,0 & 199,5 & 27,9 & \\
\hline & Tornozelo MD & 193,1 & 189,9 & 37,4 & \\
\hline & Tornozelo MND & 196,7 & 205,9 & 43,0 & \\
\hline
\end{tabular}




\begin{tabular}{|c|c|c|c|c|c|}
\hline Variáveis da pré & emporada (n=92) & Médias & Medianas & $\begin{array}{c}\text { Desvio } \\
\text { Padrão }\end{array}$ & $p$-valor \\
\hline \multirow{6}{*}{$\begin{array}{l}\text { Trabalho total } \\
\text { flexor a } 60^{\circ} / \mathrm{s} \text { do } \\
\text { membro não } \\
\text { dominante }\end{array}$} & Coxa MD & 188,5 & 197,0 & 39,9 & \multirow{6}{*}{0,366} \\
\hline & Coxa MND & 201,5 & 202,4 & 27,8 & \\
\hline & Joelho MD & 174,7 & 180,1 & 32,5 & \\
\hline & Joelho MND & 190,3 & 203,5 & 29,1 & \\
\hline & Tornozelo MD & 173,0 & 181,8 & 33,0 & \\
\hline & Tornozelo MND & 194,0 & 203,6 & 17,9 & \\
\hline \multirow{6}{*}{$\begin{array}{l}\text { Trabalho total } \\
\text { extensor a } 60^{\circ} / \mathrm{s} \\
\text { do membro } \\
\text { dominante }\end{array}$} & Coxa MD & 296,6 & 284,9 & 56,1 & \multirow{6}{*}{0,900} \\
\hline & Coxa MND & 301,7 & 305,1 & 37,2 & \\
\hline & Joelho MD & 281,7 & 266,1 & 39,2 & \\
\hline & Joelho MND & 291,4 & 311,8 & 45,3 & \\
\hline & Tornozelo MD & 307,7 & 288,2 & 63,3 & \\
\hline & Tornozelo MND & 303,2 & 312,6 & 36,9 & \\
\hline \multirow{6}{*}{$\begin{array}{c}\text { Trabalho total } \\
\text { extensor a } 60^{\circ} / \mathrm{s} \\
\text { do membro não } \\
\text { dominante }\end{array}$} & Coxa MD & 296,4 & 289,9 & 48,3 & \multirow{6}{*}{0,535} \\
\hline & Coxa MND & 324,6 & 293,8 & 73,6 & \\
\hline & Joelho MD & 276,7 & 274,4 & 40,9 & \\
\hline & Joelho MND & 328,1 & 316,7 & 72,1 & \\
\hline & Tornozelo MD & 297,9 & 289,7 & 57,3 & \\
\hline & Tornozelo MND & 321,1 & 320,9 & 28,7 & \\
\hline \multirow{6}{*}{$\begin{array}{c}\text { Trabalho total } \\
\text { flexor a } 180^{\circ} / \mathrm{s} \text { do } \\
\text { membro } \\
\text { dominante }\end{array}$} & Coxa MD & 152,5 & 155,5 & 22,3 & \multirow{6}{*}{0,200} \\
\hline & Coxa MND & 145,7 & 155,2 & 38,9 & \\
\hline & Joelho MD & 136,1 & 127,6 & 27,5 & \\
\hline & Joelho MND & 102,3 & 97,0 & 31,3 & \\
\hline & Tornozelo MD & 144,1 & 142,7 & 30,3 & \\
\hline & Tornozelo MND & 140,9 & 134,5 & 31,0 & \\
\hline \multirow{6}{*}{$\begin{array}{l}\text { Trabalho total } \\
\text { flexor a } 180^{\circ} / \mathrm{s} \text { do } \\
\text { membro não } \\
\text { dominante }\end{array}$} & Coxa MD & 130,0 & 142,4 & 33,9 & \multirow{6}{*}{0,633} \\
\hline & Coxa MND & 142,7 & 137,7 & 17,8 & \\
\hline & Joelho MD & 123,1 & 118,8 & 40,1 & \\
\hline & Joelho MND & 124,7 & 128,2 & 24,8 & \\
\hline & Tornozelo MD & 118,7 & 125,6 & 40,3 & \\
\hline & Tornozelo MND & 138,2 & 141,5 & 30,9 & \\
\hline \multirow{6}{*}{$\begin{array}{l}\text { Trabalho total } \\
\text { extensor a } 180^{\circ} / \mathrm{s} \\
\text { do membro } \\
\text { dominante }\end{array}$} & Coxa MD & 232,3 & 224,6 & 37,2 & \multirow{6}{*}{0,883} \\
\hline & Coxa MND & 238,9 & 241,6 & 28,5 & \\
\hline & Joelho MD & 220,9 & 223,8 & 30,1 & \\
\hline & Joelho MND & 225,5 & 227,0 & 38,2 & \\
\hline & Tornozelo MD & 224,4 & 219,2 & 50,2 & \\
\hline & Tornozelo MND & 221,4 & 228,6 & 31,9 & \\
\hline \multirow{6}{*}{$\begin{array}{l}\text { Trabalho total } \\
\text { extensor a } 180^{\circ} / \mathrm{s} \\
\text { do membro não } \\
\text { dominante }\end{array}$} & Coxa MD & 221,9 & 214,2 & 29,7 & \multirow{6}{*}{0,524} \\
\hline & Coxa MND & 253,0 & 253,1 & 31,7 & \\
\hline & Joelho MD & 227,4 & 238,9 & 32,0 & \\
\hline & Joelho MND & 247,1 & 238,4 & 33,4 & \\
\hline & Tornozelo MD & 218,5 & 213,7 & 56,0 & \\
\hline & Tornozelo MND & 238,6 & 232,9 & 24,2 & \\
\hline
\end{tabular}




\begin{tabular}{|c|c|c|c|c|c|}
\hline \multicolumn{2}{|c|}{ Variáveis da pré temporada $(\mathrm{n}=92)$} & \multirow{2}{*}{$\begin{array}{c}\text { Médias } \\
659,6 \\
\end{array}$} & \multirow{2}{*}{$\begin{array}{c}\text { Medianas } \\
627,0 \\
\end{array}$} & \multirow{2}{*}{$\begin{array}{c}\begin{array}{c}\text { Desvio } \\
\text { Padrão }\end{array} \\
114,4\end{array}$} & $p$-valor \\
\hline \multirow{6}{*}{$\begin{array}{l}\text { Trabalho total } \\
\text { flexor de todas as } \\
\text { repetições a } 60^{\circ} / \mathrm{s} \\
\text { do membro } \\
\text { dominante }\end{array}$} & Coxa MD & & & & \multirow{6}{*}{0,883} \\
\hline & Coxa MND & 655,0 & 677,5 & 106,8 & \\
\hline & Joelho MD & 608,9 & 588,0 & 106,7 & \\
\hline & Joelho MND & 565,4 & 580,0 & 134,0 & \\
\hline & Tornozelo MD & 613,3 & 633,0 & 137,5 & \\
\hline & Tornozelo MND & 602,6 & 633,0 & 196,6 & \\
\hline \multirow{6}{*}{$\begin{array}{l}\text { Trabalho total } \\
\text { flexor de todas as } \\
\text { repetições a } 60^{\circ} / \mathrm{s} \\
\text { do membro não } \\
\text { dominante }\end{array}$} & Coxa MD & 616,9 & 591,0 & 136,8 & \multirow{6}{*}{0,589} \\
\hline & Coxa MND & 631,2 & 667,5 & 106,9 & \\
\hline & Joelho MD & 543,7 & 565,0 & 134,4 & \\
\hline & Joelho MND & 583,6 & 624,0 & 122,5 & \\
\hline & Tornozelo MD & 531,3 & 496,0 & 168,0 & \\
\hline & Tornozelo MND & 600,0 & 585,0 & 176,3 & \\
\hline \multirow{6}{*}{$\begin{array}{c}\text { Trabalho total } \\
\text { flexor de todas as } \\
\text { repetições } \\
\text { a } 180^{\circ} / \mathrm{s} \text { do } \\
\text { membro } \\
\text { dominante }\end{array}$} & Coxa MD & 488,5 & 454,5 & 126,2 & \multirow{6}{*}{0,231} \\
\hline & Coxa MND & 467,2 & 520,0 & 161,1 & \\
\hline & Joelho MD & 444,6 & 400,0 & 106,1 & \\
\hline & Joelho MND & 272,8 & 204,0 & 146,5 & \\
\hline & Tornozelo MD & 435,5 & 400,0 & 142,5 & \\
\hline & Tornozelo MND & 413,9 & 437,0 & 205,0 & \\
\hline \multirow{6}{*}{$\begin{array}{c}\text { Trabalho total } \\
\text { flexor de todas as } \\
\text { repetições a } \\
180^{\circ} / \mathrm{s} \text { do } \\
\text { membro não } \\
\text { dominante }\end{array}$} & Coxa MD & 434,0 & 480,0 & 155,5 & \multirow{6}{*}{0,456} \\
\hline & Coxa MND & 445,0 & 408,5 & 96,1 & \\
\hline & Joelho MD & 382,0 & 357,0 & 138,0 & \\
\hline & Joelho MND & 359,0 & 376,0 & 104,8 & \\
\hline & Tornozelo MD & 332,1 & 319,0 & 183,1 & \\
\hline & Tornozelo MND & 447,0 & 426,0 & 155,7 & \\
\hline \multirow{6}{*}{$\begin{array}{l}\text { Trabalho total } \\
\text { extensor de todas } \\
\text { as repetições a } \\
60^{\circ} / \mathrm{s} \text { do membro } \\
\text { dominante }\end{array}$} & Coxa MD & 607,0 & 686,5 & 356,5 & \multirow{6}{*}{0,970} \\
\hline & Coxa MND & 552,3 & 582,0 & 419,0 & \\
\hline & Joelho MD & 594,6 & 802,0 & 367,0 & \\
\hline & Joelho MND & 583,8 & 684,0 & 355,4 & \\
\hline & Tornozelo MD & 509,1 & 411,0 & 347,4 & \\
\hline & Tornozelo MND & 528,3 & 684,0 & 327,6 & \\
\hline \multirow{6}{*}{$\begin{array}{l}\text { Trabalho total } \\
\text { extensor de todas } \\
\text { as repetições a } \\
60^{\circ} / \mathrm{s} \text { do membro } \\
\text { não dominante }\end{array}$} & Coxa MD & 597,9 & 719,0 & 357,2 & \multirow{6}{*}{0,925} \\
\hline & Coxa MND & 555,2 & 607,5 & 406,5 & \\
\hline & Joelho MD & 596,6 & 871,0 & 409,3 & \\
\hline & Joelho MND & 637,6 & 829,0 & 350,9 & \\
\hline & Tornozelo MD & 481,8 & 330,0 & 358,0 & \\
\hline & Tornozelo MND & 585,6 & 734,0 & 315,7 & \\
\hline \multirow{6}{*}{$\begin{array}{c}\text { Trabalho total } \\
\text { extensor de todas } \\
\text { as repetições a } \\
180^{\circ} / \mathrm{s} \text { do } \\
\text { membro } \\
\text { dominante }\end{array}$} & Coxa MD & 756,5 & 758,5 & 78,9 & \multirow{6}{*}{0,808} \\
\hline & Coxa MND & 793,7 & 814,0 & 103,0 & \\
\hline & Joelho MD & 745,0 & 742,0 & 102,0 & \\
\hline & Joelho MND & 661,6 & 655,0 & 167,2 & \\
\hline & Tornozelo MD & 723,3 & 753,0 & 155,5 & \\
\hline & Tornozelo MND & 724,1 & 743,0 & 178,9 & \\
\hline
\end{tabular}




\begin{tabular}{|c|c|c|c|c|c|}
\hline \multicolumn{2}{|c|}{ Variáveis da pré temporada $(n=92)$} & Médias & Medianas & $\begin{array}{l}\text { Desvio } \\
\text { Padrão }\end{array}$ & $p$-valor \\
\hline \multirow{6}{*}{$\begin{array}{c}\text { Trabalho total } \\
\text { extensor de todas } \\
\text { as repetições a } \\
180^{\circ} / \text { s do } \\
\text { membro não } \\
\text { dominante }\end{array}$} & Coxa MD & 744,9 & 739,5 & 201,3 & \multirow{6}{*}{0,892} \\
\hline & Coxa MND & 801,3 & 816,0 & 73,4 & \\
\hline & Joelho MD & 783,7 & 796,0 & 103,6 & \\
\hline & Joelho MND & 738,6 & 754,0 & 110,0 & \\
\hline & Tornozelo MD & 688,5 & 753,0 & 244,9 & \\
\hline & Tornozelo MND & 816,6 & 935,0 & 173,0 & \\
\hline \multirow{6}{*}{$\begin{array}{c}\text { Relação } \\
\text { flexora/extensora } \\
\text { a } 60^{\circ} / \mathrm{s} \text { do } \\
\text { membro } \\
\text { dominante }\end{array}$} & Coxa MD & 60,6 & 60,9 & 9,2 & \multirow{6}{*}{0,878} \\
\hline & Coxa MND & 60,9 & 61,1 & 5,6 & \\
\hline & Joelho MD & 57,7 & 53,9 & 13,5 & \\
\hline & Joelho MND & 63,0 & 59,3 & 9,1 & \\
\hline & Tornozelo MD & 58,9 & 58,6 & 7,9 & \\
\hline & Tornozelo MND & 61,8 & 64,4 & 13,1 & \\
\hline \multirow{6}{*}{$\begin{array}{c}\text { Relação } \\
\text { flexora/extensora } \\
\text { a } 60^{\circ} / \text { s do } \\
\text { membro não } \\
\text { dominante }\end{array}$} & Coxa MD & 57,9 & 59,1 & 6,5 & \multirow{6}{*}{0,412} \\
\hline & Coxa MND & 58,7 & 59,3 & 9,3 & \\
\hline & Joelho MD & 51,7 & 51,6 & 10,2 & \\
\hline & Joelho MND & 57,7 & 60,7 & 7,0 & \\
\hline & Tornozelo MD & 53,9 & 54,1 & 5,2 & \\
\hline & Tornozelo MND & 57,2 & 58,9 & 5,6 & \\
\hline
\end{tabular}

Legenda: MD: membro dominante; MND: membro não dominante; *diferença significante $(\mathrm{p}<0,05)$

conclusão 
Anexo H - Valores médios, medianas, desvio padrão (DP) e $p$-valor dos déficits dos músculos flexores e extensores do joelho do membro dominante e não dominante corrigidos pela massa corporal e expressos em porcentagem nas velocidades de $60 \%$ s e $180 \%$ s na pré temporada dos 92 sujeitos, segundo as lesões musculoesqueléticas mais prevalentes

\begin{tabular}{|c|c|c|c|c|c|}
\hline \multicolumn{2}{|c|}{ Déficit na pré temporada (n=92) } & Média & Mediana & $\begin{array}{c}\text { Desvio } \\
\text { Padrão }\end{array}$ & $p$-valor \\
\hline \multirow{6}{*}{$\begin{array}{l}\text { Déficit no } \\
\text { pico de } \\
\text { torque } \\
\text { flexor a } \\
60^{\circ} / \mathrm{s}\end{array}$} & Coxa MD & 8,0 & 5,5 & 8,3 & \multirow{6}{*}{0,682} \\
\hline & Coxa MND & 9,0 & 6,0 & 9,2 & \\
\hline & Joelho MD & 6,1 & 6,0 & 6,7 & \\
\hline & Joelho MND & 7,0 & 7,0 & 4,6 & \\
\hline & Tornozelo MD & 10,9 & 10,0 & 7,8 & \\
\hline & Tornozelo MND & 9,9 & 6,0 & 9,4 & \\
\hline \multirow{6}{*}{$\begin{array}{l}\text { Déficit no } \\
\text { pico de } \\
\text { torque } \\
\text { extensor a } \\
60^{\circ} / \mathrm{s}\end{array}$} & Coxa MD & 7,4 & 7,5 & 5,2 & \multirow{6}{*}{0,461} \\
\hline & Coxa MND & 11,5 & 8,5 & 7,2 & \\
\hline & Joelho MD & 7,9 & 5,0 & 5,3 & \\
\hline & Joelho MND & 13,4 & 13,0 & 9,1 & \\
\hline & Tornozelo MD & 7,5 & 6,0 & 6,0 & \\
\hline & Tornozelo MND & 10,7 & 10,0 & 6,5 & \\
\hline \multirow{6}{*}{$\begin{array}{l}\text { Déficit no } \\
\text { trabalho } \\
\text { total flexor } \\
\text { a } 60^{\circ} \% \mathrm{~s}\end{array}$} & Coxa MD & 9,1 & 8,0 & 6,6 & \multirow{6}{*}{0,460} \\
\hline & Coxa MND & 11,0 & 8,0 & 9,8 & \\
\hline & Joelho MD & 7,9 & 5,0 & 9,5 & \\
\hline & Joelho MND & 25,6 & 31,0 & 22,1 & \\
\hline & Tornozelo MD & 14,1 & 14,0 & 11,8 & \\
\hline & Tornozelo MND & 18,7 & 17,0 & 16,0 & \\
\hline \multirow{6}{*}{$\begin{array}{l}\text { Déficit no } \\
\text { trabalho } \\
\text { total } \\
\text { extensor a } \\
60^{\circ} / \mathrm{s}\end{array}$} & Coxa MD & 5,3 & 4,0 & 2,9 & \multirow{6}{*}{0,567} \\
\hline & Coxa MND & 11,7 & 9,5 & 10,9 & \\
\hline & Joelho MD & 5,6 & 4,0 & 5,0 & \\
\hline & Joelho MND & 13,4 & 12,0 & 13,2 & \\
\hline & Tornozelo MD & 8,0 & 8,0 & 4,2 & \\
\hline & Tornozelo MND & 7,7 & 7,0 & 6,2 & \\
\hline \multirow{6}{*}{$\begin{array}{l}\text { Déficit no } \\
\text { trabalho } \\
\text { total flexor } \\
\text { a } 180^{\circ} \% \mathrm{~s}\end{array}$} & Coxa MD & 15,8 & 9,5 & 22,2 & \multirow{6}{*}{0,565} \\
\hline & Coxa MND & 18,2 & 9,0 & 23,9 & \\
\hline & Joelho MD & 15,9 & 5,0 & 16,9 & \\
\hline & Joelho MND & 29,0 & 12,0 & 29,6 & \\
\hline & Tornozelo MD & 19,9 & 16,0 & 17,2 & \\
\hline & Tornozelo MND & 9,6 & 8,0 & 7,7 & \\
\hline
\end{tabular}




\begin{tabular}{|c|c|c|c|c|c|}
\hline \multicolumn{2}{|c|}{ Déficit na pré temporada $(n=92)$} & Média & Mediana & $\begin{array}{c}\text { Desvio } \\
\text { Padrão }\end{array}$ & $p$-valor \\
\hline \multirow{6}{*}{$\begin{array}{c}\text { Déficit no } \\
\text { trabalho } \\
\text { total } \\
\text { extensor a } \\
180^{\circ} / \mathrm{s}\end{array}$} & Coxa MD & 10,9 & 7,5 & 12,8 & \multirow{6}{*}{0,778} \\
\hline & Coxa MND & 7,7 & 8,0 & 4,9 & \\
\hline & Joelho MD & 5,0 & 5,0 & 3,4 & \\
\hline & Joelho MND & 10,6 & 8,0 & 9,8 & \\
\hline & Tornozelo MD & 11,3 & 9,0 & 11,1 & \\
\hline & Tornozelo MND & 10,6 & 8,0 & 9,2 & \\
\hline \multirow{6}{*}{$\begin{array}{l}\text { Déficit no } \\
\text { trabalho } \\
\text { total flexor } \\
\text { de todas as } \\
\text { repetições } \\
\text { a } 60 \% \mathrm{~s}\end{array}$} & Coxa MD & 8,0 & 5,5 & 8,7 & \multirow{6}{*}{0,615} \\
\hline & Coxa MND & 12,0 & 6,0 & 13,1 & \\
\hline & Joelho MD & 14,9 & 3,0 & 21,5 & \\
\hline & Joelho MND & 23,6 & 22,0 & 20,7 & \\
\hline & Tornozelo MD & 19,5 & 14,0 & 19,3 & \\
\hline & Tornozelo MND & 17,1 & 7,0 & 19,6 & \\
\hline \multirow{6}{*}{$\begin{array}{l}\text { Déficit no } \\
\text { trabalho } \\
\text { total flexor } \\
\text { de todas as } \\
\text { repetições } \\
\text { a } 180^{\circ} / \mathrm{s}\end{array}$} & Coxa MD & 20,5 & 14,0 & 25,8 & \multirow{6}{*}{0,292} \\
\hline & Coxa MND & 27,5 & 18,5 & 29,0 & \\
\hline & Joelho MD & 23,4 & 13,0 & 24,7 & \\
\hline & Joelho MND & 35,2 & 15,0 & 37,3 & \\
\hline & Tornozelo MD & 34,0 & 23,0 & 26,6 & \\
\hline & Tornozelo MND & 11,0 & 11,0 & 8,0 & \\
\hline \multirow{6}{*}{$\begin{array}{l}\text { Déficit no } \\
\text { trabalho } \\
\text { total } \\
\text { extensor de } \\
\text { todas as } \\
\text { repetições } \\
\text { a } 60^{\circ} / \mathrm{s}\end{array}$} & Coxa MD & 5,1 & 4,0 & 4,1 & \multirow{6}{*}{0,571} \\
\hline & Coxa MND & 10,8 & 8,0 & 11,3 & \\
\hline & Joelho MD & 4,7 & 3,0 & 4,0 & \\
\hline & Joelho MND & 14,6 & 20,0 & 11,9 & \\
\hline & Tornozelo MD & 6,9 & 7,0 & 4,6 & \\
\hline & Tornozelo MND & 13,7 & 8,0 & 12,6 & \\
\hline \multirow{6}{*}{$\begin{array}{l}\text { Déficit no } \\
\text { trabalho } \\
\text { total } \\
\text { extensor de } \\
\text { todas as } \\
\text { repetições } \\
\text { a } 180^{\circ} \% \mathrm{~s}\end{array}$} & Coxa MD & 14,6 & 4,0 & 20,6 & \multirow{6}{*}{0,251} \\
\hline & Coxa MND & 6,2 & 5,0 & 7,4 & \\
\hline & Joelho MD & 6,1 & 4,0 & 3,5 & \\
\hline & Joelho MND & 13,8 & 13,0 & 14,4 & \\
\hline & Tornozelo MD & 19,0 & 9,0 & 17,0 & \\
\hline & Tornozelo MND & 16,0 & 15,0 & 14,7 & \\
\hline
\end{tabular}

Legenda: MD: membro dominante; MND: membro não dominante; *diferença significante $(\mathrm{p}<0,05)$ 


\section{REFERÊNCIAS}

Alison S, Westpmol K, Finstuen K. Knee Extension and flexion torque as function of thigh asymmetry. J Ort Sports Phys Ther. 1993; 18(6): 661-666.

Akova GH, Pündük Z, Küçükoglu S. Effects of age on the reciprocal peak torque ratios during knee muscle contrations in elite soccer players. Scand J Med Sci Sports. 1999; 9(2): 81-87.

Araújo CG, vilas-boas F, Yazbeck P, Stein R. Teste ergométrico em associação com outros métodos. Arq Bras Cardiol. 2002; 78: 2 (Supl).

Arnason A, Gudmundsson A, Dahl HA, Johannsson E. Soccer injuries in Iceland. Scand J Med Sci Sports. 1996; 6(1): 40-45.

Barbanti VJ. Treinamento físico: bases científicas. São Paulo: CLR Balieiro, 1996.

Becker Júnior B, Samulski D. Manual de treinamento psicológico para o esporte. Porto Alegre: Feevale, 1998.

Bennell K, Wajswelner PL, Schall- Riaucour A, Leslie S, Plant D, Cirone J. Isokinetic strength testing does not predict hamstring injury in Australian Rules footballers. Br J Sports Med. 1998; 32(4): 309-314.

Brynhildsen J, Ekstrand J, Jeppsson A, Tropp H. Previous injuries and persisting symptoms in female soccer players. Int J Sports Med. 1990; 11(6): 489-492.

Bjordal JM, Arnly F, Hannestad B, Strand T. Epidemiology of anterior cruciate ligament injuries in soccer. Am J Sporst Med. 1997; 25(3): 341-345.

Carazzato JG, Campos LAN, Carazzato SG. Incidência de lesões traumáticas em atletas competitivos de dez tipos de modalidades esportivas. Rev Bras Ortop. 1992; 27(10): 745-758.

CBFS. Confederação Brasileira de Futebol de Salão. 2001. Disponível em: http://www.cbfs.com.br.

Cohen M, Abdalla RJ, Ejnisman B, Amaro JT. Lesões ortopédicas no futebol. Rev Bras Ortop. 1997; 32(12): 940-944.

Cohen M, Abdalla RJ. Lesões nos esportes. Rio de Janeiro: Revinter; 2002. 
Cometti G, Maffiuletti NA, Pousson M, Chatard JC, Maffulli N. Isokinetic strength and anaerobic power of elite, subelite and amateur French soccer players. Int J Sports Med. 2001; 22(1): 45-51.

Conover W. Pratical nonparametric statistics. Nova York: Jonh Willy \& Sons, 1971.

Cybex norm. Testing \& Reabilitation System - User's Guide. Cybex Internacional Blue Sky Softweare. Estados Unidos da América, 1996.

D' Alessandro RL, Silveira EAP, Anjos MTS. Análise da associação entre a dinamometria isocinética da articulação do joelho e o salto horizontal unipodal, hop test, em atletas de voleibol. Rev Bras Med Esporte. 2005; 11(5): 271-275.

D'Hooge M, Watteyne R, Deneve J. Locomotor injuries in young players. Blackwell Scientific Publications. 1994: 195-197.

Dvir Z. Isocinética: avaliações musculares, interpretações e aplicações clínicas. São Paulo: Manole, 2002.

Ekstrand J, Gillquist J. Soccer injuries and their mechanisms: a prospective study. Med Sci Sports Exerc. 1983; 15(3): 267-270.

Ekstrand J, Gillquist J, Lijedahl SO. Prevention of soccer injuries. Supervision by doctor and physiotherapist. Am J Sports Me d. 1983; 1(3): 116-120.

EkstrandJj, Nigg BM. Surface- related injuries in soccer. Sports Med. 1989; 8(1): 5662.

Engström B, Forssblad M, Johansson C, Törnkvist H. Does a major knee injury definitely sideline an elite soccer player? Am J Sports Med. 1990; 18(1): 101-105.

Ergün M, Islegen C, Taskiran E. A cross- sectional analysis of sagittal knee laxity and isokinetic muscle strength in soccer players. Int J Sports Med. 2004; 25(8): 594-598.

Feigenbaum MM, Pollock M. Prescription of resistence training for health and disease. Med Sci Sports Exerc. 1999; 1(1): 38-45.

FIFA. Regras oficias. 2001; Disponível em: http:// www.fifa.com.

Gioftsidou A, Beneka A, Malliou P, Pafis G, Godolias G. Soccer players' muscular imbalances: restoration with an isokinetic strength training program. Percept Mot Skills. 2006; 103(1): 151-159.

Ghorayeb N, Barros T. O exercício. São Paulo: Atheneu, 1999. 
Goslin BR, Charteris J. Isokinetic dynamometry: normative data for clinical use in lower extremity (knee) cases. Scand J Rehab Med. 1979; 11(3): 105- 109.

Greve JMD. Tratado de Medicina de Reabilitação. São Paulo: Roca, 2007.

Guillet R, Genety J, Brunet- Guedj E. Medicina do Esporte. São Paulo: Masson, 1993.

Guyton AC, Hall JE. Tratado de fisiologia médica. Rio de Janeiro: Guanabara Koogan, 1997.

Hagood S, Solomonow M, Baratta R, Zhou BH, D'Ambrosia R. The effect of joint velocity on the contribution of the antagonist musculature to knee stiffness and laxity. Am J Sports Med. 1990; 18(2): 182-187.

Inklar H. Soccer injuries. Sports Med. 1994; 18(1): 55-73.

Junge A, Dvorak J. Football injuries and physical symptoms. Am J Sports Med. 2000a; 28(5) (Supl): 3-9.

Junge A, Dvorak J. Incidence of football injuries and complaints in different age groups and skill-level groups. Am J Sports Med. 2000b; 28(5) (Supl): 51-57.

Junge A, Dvorak J. Soccer injuries. Sports Med. 2004; 34(13): 929-938.

Júnior NB. A ciência do esporte aplicada ao futsal. Rio de Janeiro: Sprint, 1999.

Kalapotharakos VI, Strimpakos N, Vithoulka I, Karvounidis C, Diamantopoulos k, Kapreli E. Physiological characteristics of elite professional soccer teams of different ranking. J Sports Med Phys Fitness. 2006; 46(4): 515-519.

Lindenfeld TN, Schmitt DJ, Hendy MP, Mangine RE, Noyes FR. Incidence of injury in indoor soccer. Am J Sports Med. 1994; 22(3): 364-371.

Magalhães J, Oliveira J, Ascensão A, Soares J. Concentric quadriceps and hamstrings isokinetic strength in volleyball and soccer players. J Sports Med Phys Fitness. 2004; 44(2): 119-125.

Mcardle W, Katch F, Katch V. Fisiologia do exercício: energia, nutrição e desempenho humano. Rio de Janeiro: Guanabara Koogan, 1998.

Marroco J. Análise estatísitica com utilização do SPSS. Lisboa: Silabo, 2003.

Mcmaster WC, Walter M. Injuries in soccer. Am J Sports Med. 1978; 6(6): 354-357. 
Melo JD. Esportes de quadra. Rio de Janeiro: Sprint; 1999.

Metzel JD, Micheli LJ. Youth soccer: an epidemiologic perspective. Clin Sports Med. 1998; 17(4): 663-673.

Murray R. Estatística Coleção Schaum. São Paulo: Afiliada, 1993.

Newman MA, Tarpenning KM, Marino FE. Relationships between isokinetic knee strength, single- sprint performance, and repeated- sprint ability in football players. $J$ Strength Cond Res. 2004; 18(4): 867-872.

Nielsen AB, Johannes Y. Epidemiology and traumatology of injuries in soccer. Am J Sports Med. 1989; 17(6): 803-807.

Noyes FR, Keller CS, Buncher CR. The medical aspects of soccer injury epidemiology. Am J Sports Med. 1988; 16: 1 (Supl): 105-112.

Pedrinelli A. Incidência de lesões traumáticas em atletas de futebol. [Dissertação]. São Paulo: Faculdade de Medicina da Universidade de São Paulo; 1994.

Perrin D. Isokinetic exercise and assessment. Virgínia: Human Kinetics Publishers, 1993.

Prati FA. Lesões: fatores desencadeantes e prevenção. Fisioterapia em Movimento. 1992; 5(1): 9-20.

Putukian M, Knowles WK, Scott S, Castle NG. Injuries in indoor soccer. Am J Sports Med. 1996; 24(3): 317-322.

Ribeiro RN, Costa LOP. Análise epidemiológica de lesões no futebol de salão durante o VX Campeonato Brasileiro de Seleções Sub 20. Rev Bras Med Esporte. 2006; 12(1): 1-5.

Ribeiro CZP, Akashi PMH, Sacco ICN, Pedrinelli A. Relação entre alterações posturais e lesões no aparelho locomotor em atletas de futebol de salão. Rev Bras Med Esporte. 2003; 9(2): 91-97.

Schmidt-Olsen S, Jorgensen U, Kaalund S, Sorensen J. Injuries among young soccer players. Am J Sports Med. 1991; 19(3): 273-275.

Serrão JC, Sa MR, Amadio AC. Influência dos calçados de futsal no desempenho. Rev Bras Biomec. 2000; 1(1): 39-47. 
Siqueira CM, Pelegrine FRMM, Fontana MF, Greve JMD. Isokinetic dynamometry of knee flexors and extensors: comparative study among non-athletes, jumper athletes and runner athletes. Rev Hosp Clin Fac Med S Paulo. 2002; 51(1): 19-24.

Shinzato GT, Batistella LR. Exercício isocinético - sua utilização para avaliação e reabilitação músculo esquelética. Am Med Desport. 1996: 1(1): 11-18.

Stewien ETM, Camargo OPA. Ocorrência de entorse e lesões do joelho em jogadores de futebol da cidade de Manaus, Amazonas. Acta Ortop Bras. 2005; 13(3): 141-146.

Sullivan JA, Gross RH, Grana WA, Garcia-Moral CA. Evaluation of injuries in youth soccer. Am J Sports Med. 1980; 8(5): 325-327.

Terreri ASAP, Greve JMD, Amatuzzi MM. Avaliação isocinética no joelho do atleta. Rev Bras Med Esporte. 2001; 7(5): 170-174.

USFF. United States Futsal Federation. 2001. Disponível em: http://www.futsal.org.

Vieira S. Introdução à Bioestatística. Rio de Janeiro: Campus, 1991.

Vieura S. Bioestatísticas: tópicos avançados. Rio de Janeiro: Campus, 2004.

Wrigley TV, Grant M. Sports physiotherapy- Applied Science Pratice. Austrália: Churchill Lungstone, 1995.

Wrigley TV. Assessment for football: soccer, Australian rules, and American. Isokinetics in human performance. Champaign: Human Kinetics, 2000.

Zakas A, Mandroukas K, Vamvakoudis K, Christoulas N, Aggelopoulou N. Peak torque of quadriceps and hamstring muscles in basketball and soccer players of different divisions. J Sports Med Phys Fitness. 1995; 35(3): 199-294.

Zakas A. Bilateral isokinetic peak torque of quadriceps and hamstring muscles in professional soccer players with dominance on one or both two sides. J Sports Med Phys Fitness. 2006; 46(1): 28-35. 